\title{
Sexual maturation and changes in water and salt transport components in the kidney and intestine of three-spined stickleback (Gasterosteus aculeatus L.).
}

\author{
Steffen S. Madsen ${ }^{\mathrm{a}}$, Claus Weber ${ }^{\mathrm{a}}$, Andreas M. Nielsen ${ }^{\mathrm{a}}$, Mohammad Mohiseni ${ }^{\mathrm{c}}$, Maryline C. \\ Bosssus $^{\text {b }}$, Christian K. Tipsmark ${ }^{b}$ and Bertil Borg ${ }^{d}$ \\ ${ }^{a}$ Department of Biology, University of Southern Denmark, Campusvej 55, DK-5230 Odense \\ Denmark \\ ${ }^{b}$ Department of Biological Sciences, University of Arkansas, SCEN 601, Fayetteville, AR 72701, \\ USA \\ ${ }^{c}$ Behbahan Khatam Alanbia University of Technology, Iran \\ ${ }^{d}$ Department of Zoology, Stockholm University, S-106 91 Stockholm, Sweden
}

ms has 24 pages, 8 figures and 2 tables

Running title: Intestine and kidney function in mature male stickleback

* Corresponding author:

Dr. Steffen S. Madsen,

Department of Biology,

University of Southern Denmark,

Campusvej 55, DK-5230 Odense,

Denmark.

Tel: +4565502450

email: steffen@biology.sdu.dk; 


\begin{abstract}
Mature three-spined stickleback males use spiggin threads secreted from their kidney to glue together nest material. This requires strongly hypertrophied renal proximal tubular cells, which compromises renal osmoregulatory function during the breeding period. There is experimental evidence that the intestine takes over hypotonic fluid secretion at that stage but the mechanism is unexplored. To unravel the mechanism behind this unique physiological function, we analyzed and compared transcript levels of several membrane proteins, known to be involved in water and salt transport in intestinal and renal tissues, in non-mature males (NM), mature males (MM) and mature females (MF). Aquaporin paralogs aqpla, $-3 a,-8 a a,-8 a b,-10 a$, and $-10 b$, two $\mathrm{Na}^{+}, \mathrm{K}^{+}-\mathrm{ATPa} e$ alpha-1 subunit isoforms (nka547, nka976), $\mathrm{Na}^{+}, \mathrm{K}^{+}, 2 \mathrm{Cl}^{-}$- and $\mathrm{Na}^{+}, \mathrm{Cl}^{-}$-cotransporters (nkccla, $n k c c 2, n c c$ ), the cystic fibrosis transmembrane conductance regulator ( $c f t r)$ and two claudin isoforms (cldn2, cldn15a) were expressed in the intestine and kidney in all groups. There were no differences in aqp and $c l d n$ expression between intestines of NM and MM; $n k c c 2$ was lower and $n k a$ levels tended to be higher in intestines of MM than in NM. In the kidney, aqp1 and aqp8ab levels were lower in MM than in NM, whereas aqp3a, nkccla, cldn15a and spiggin were markedly elevated. This was accompanied by marked hypertrophy of kidney tubules in MM. The data support an altered kidney function in terms of water handling in mature males, whereas there was no support for modified trans-epithelial water permeability or salt-secretory activity in the intestine of mature males. Salt-absorptive activity in the intestine may, however, be down-regulated during male maturation.
\end{abstract}

Keywords: aquaporin, claudin, ion-transporter, kidney, intestine, stickleback, spiggin 


\section{Introduction}

Among invertebrates there are several examples of extraorganismal proteins being secreted in bulk amounts with the purpose of attachment, building hunting webs, cocoons, etc. (Tsuda et al., 1979; Devore et al., 1984; Gosline et al., 1999; Mondal et al., 2007). Vertebrates on the other hand only rarely use such engineering skills. One example which has long fascinated zoologists occurs among males of the teleostean stickleback family (Gasterosteidae), where nest building occurs aided by a glue-like proteinaceous substance secreted from the kidney tubules and stored in the urinary bladder. In a pioneering record Möbius (1885) pointed out that the secreted thin threads originated from the kidney in the male fifteen-spined stickleback, Spinachia spinachia. Later Hess (1918) described the fascinating anatomical transformation of the kidney in the five-spined stickleback Culaea (Eucalia) inconstans, during its annual reproductive cycle. Primarily the cells of the secondary proximal tubular epithelium transform into a secretory epithelium, producing bulk amounts of a sticky protein, which years later was characterized, sequenced and given the name "spiggin", named after "spigg" meaning stickleback in Swedish (Jakobsson et al., 1999; Jones et al., 2001).

The three-spined stickleback (Gasterosteus aculeatus) occurs widespread in the Holarctic region and may live and reproduce in freshwater (FW), brackish water as well as coastal marine environments. In anadromous and thus euryhaline populations sexual maturation occurs in the late spring, where the fish seek residence in FW or low-salinity brackish water. In the male, 11ketoandrogens are efficient inducers of a pronounced structural reorganization and hypertrophy of the secondary proximal and collecting tubule epithelia cells (De Ruiter and Mein, 1982; Borg et al., 1993), which become functionally compromised by the switch to synthesize and secrete spiggin. The agglutinate is stored in the bladder until used as a structural and highly elastic adhesive thread to assemble a nest in which the female lays her eggs (Hess, 1918). Very little is known about the consequences of this functional specialization for the osmoregulatory function of the kidney. Fish living in a hypotonic environment generally depend on their filtrating kidney to secrete surplus water taken up by osmosis across the gills and it appears that the production and storage of bulk amounts of a slimy, proteinaceous fluid is incompatible with a high urine output. Indeed this is what De Ruiter (1980b) reported in his thesis and subsequent publications on the hydromineral regulation of three-spined stickleback during sexual development. The pronounced kidney hypertrophy is accompanied by reduced glomerular filtration rate (GFR) and loss of ion reabsorptive capacity and leaves the kidney with a reduced osmoregulatory function. In order to maintain water balance, FW 
sticklebacks must therefore be expected to use one or more extra-renal compensatory mechanisms for water elimination. De Ruiter and Wendelaar Bonga (1985) elegantly demonstrated by use of micro-catheterization that sexually maturing males initiate secretion of a hypotonic fluid originating from their intestine, which suggests a reorganization of organ function specific to sexually mature males, since mature females do not induce this function. This was supported by development of a more extensive basolateral membrane system of the enterocytes (basal labyrinth; De Ruiter et al., 1985), which led the authors to hypothesize the development of a 'backward channel standing gradient osmotic flow function' of the intestine (Diamond and Bossert, 1967, 1968). According to this model, fluid secretion may occur across an epithelium if salt secretion is accompanied by the presence of appropriate transepithelial water permeability. Water may in principle penetrate an epithelium via para- or trans-cellular routes: De Ruiter proposed a trans-cellular pathway based on an expectation of water tight junctions between the enterocytes. No studies have, however, investigated the nature and molecular composition of intestinal tight junctions in sticklebacks or of the presence and distribution of aquaporins to facilitate water transport in this epithelium. To the best of our knowledge, intestinal fluid secretion as a natural contribution to hyperosmoregulation in fishes has never been reported before or after this discovery. In mammals, the pathophysiological condition of diarrhea is induced by bacterial endotoxins and is due to stimulated salt secretion in association with reduced water reabsorptive capacity due to mislocalization of aquaporin 2 and 3 (Field, 2003). A similar phenomenon was, however, induced in seawater-acclimated killifish (Fundulus heteroclitus) intestines when intracellular levels of $\mathrm{Ca}^{2+}$ and cAMP were stimulated pharmacologically in vitro (Marshall et al., 2002). Whether this condition reflects a physiological scenario is unknown. Recently, fluid secretion from the distal part of the intestine was induced by guanylin peptides in the Gulf toadfish, Opsanus beta, which may facilitate deposition of $\mathrm{CaCO}_{3}$ precipitates (Ruhr et al., 2014). Fluid secretion from the intestine is counterintuitive to hypo-osmoregulation in marine fishes but it may theoretically be advantageous in a FW fish. Whereas evidence for intestinal fluid secretion in fishes is scarce, it is well accepted that intestinal fluid absorption is a common compensatory mechanism for dehydration in marine fishes (Edwards and Marshall, 2013). There is evidence that osmotic water flow may occur transcellularly through aquaporins as well as para-cellularly through tight junctions (Grossell, 2011; Madsen et al., 2011). There are 13 members of the aquaporin family in mammals and even more in fishes (Tingeaud-Sequeirra et al., 2010). All aquaporins are water permeable, a subfamily - the aquaglyceroporins - have additional permeabilities to small nonpolar solutes such as urea and 
glycerol, so their function may be linked to metabolic events as well. In order to establish transcellular water movement though aquaporins, they must be present in both apical and basolateral membrane domains and a favorable osmotic gradient must be established. The permeability of tight junctions is critically controlled by proteins of the claudin family, i.e. junctions guarded by specific claudin isoforms may serve as ionic barriers or display selective permeabilities to anions, cations and water (see Angelow et al., 2008; Hou et al., 2013). Two particular claudin isoforms, claudin-2 and -15 have been shown to create water permeable junctions in other systems (zebrafish (Danio rerio) intestine: Bagnat et al., 2007; transfected MDCK C7 cells: Rosenthal et al., 2010). The energetic drive for any fluid transport across an epithelium is the simultaneous (active) transport of osmolytes (typically $\mathrm{NaCl}$ ) in order to establish favorable osmotic conditions. Thus to absorb fluid, $\mathrm{NaCl}$ must be absorbed in parallel and fluid secretion requires salt secretion followed by osmosis. This mechanism will usually transport more or less isotonic fluid. In order to secrete a hypotonic fluid, subsequent reabsorption of salt must therefore take place. This process is thus more complex and requires spatial separation of fluid secretion and salt reabsorption. Among the various ion-transport proteins involved in epithelial $\mathrm{NaCl}$ transport are basolateral $\mathrm{Na}^{+}, \mathrm{K}^{+}$-ATPase in combination with apical $\mathrm{Na}^{+}, \mathrm{K}^{+}, 2 \mathrm{Cl}^{-}(\mathrm{NKCC} 2)$ - or $\mathrm{Na}^{+}, \mathrm{Cl}^{-}(\mathrm{NCC})$-cotransport for absorption or in combination with apical CFTR and basolateral NKCC1-cotransport (for secretion). Paracellular transport of $\mathrm{NaCl}$ mediated by leaky pores created by claudins may also be involved in certain epithelia. In this study we tested the hypothetical model of these processes shown in Fig. 1. In particular we wanted to test if there is evidence of a modified transport activity in the intestine of sexually maturing stickleback males which could facilitate increased hypotonic fluid secretion. This was accomplished by analyzing and comparing transcript levels of selected aquaporins, iontransport and claudin proteins in maturing and non-maturing males. First, we analyzed the tissue distribution of the selected targets to assure their relevance and then focused the investigation on transcript levels in the intestine and kidney of sexually mature and non-mature males. Mature females were used for comparison. In line with the hypothesis of De Ruiter (1980b), our expectation was that there would be strong signs of developmental changes in both the intestine and kidney during male sexual maturation, assuming a shift in the respective roles of these two organs in eliminating hypotonic fluid. 


\section{Materials and Methods}

\subsection{Fish and sampling}

\subsubsection{Experiment 1: Tissue distribution of aquaporins}

For this part of the study 10 non-mature adult three-spined sticklebacks (Gasterosteus aculeatus, mixed sexes) were caught in brackish water (10 ppt) in the Kerteminde Fjord (Denmark) in September 2012. The fish were transported to the lab in aerated containers, and sampling took place the same day. Each fish was anaesthetized in $0.5 \mathrm{ppm}$ 2-phenoxyethanol and subsequently killed by cervical dislocation. The following tissues were excised and immediately frozen in liquid nitrogen: liver, oesophagus, brain, kidney, anterior intestine, posterior intestine, gill and gonads. The experimental procedures were approved by the Danish Animal Experiments Inspectorate in accordance with the European convention for the protection of vertebrate animals used for experiments and other scientific purposes (\#86/609/EØF).

\subsubsection{Experiment 2: Effects of sexual maturation}

Three-spined sticklebacks were originally obtained from the sea (10 ppt) near Skanör (Sweden) in the spring of 2011 and brought to the University of Stockholm. Prior to experimentation two subgroups had been held at different photo- and temperature regimes in 5 ppt artificial saltwater. Some of the fish were transferred to $\mathrm{LD} 16: 8$ at $20{ }^{\circ} \mathrm{C}$ in $5 \mathrm{ppt}$ artificial seawater for maturation soon after capture. At the time of the experiment, these fish (males) were in a post-breeding state and denoted as non-mature males (NM). The other fish were kept under winter conditions (LD 8:16 at $8{ }^{\circ} \mathrm{C}$ in similar water until September 8 when they brought into LD $16: 8$ and $18{ }^{\circ} \mathrm{C}$ to mature. On the September 16 all fish were transferred to FW and held at LD 16:8 and $18{ }^{\circ} \mathrm{C}$ until sampling. The FW was Stockholm tap water in a thoroughly cleansed 1200 L aquarium enriched with sand, tiles and algae. The fish were fed with frozen red midge larvae, mysids or Artemia salina. All fish were sampled on October 10, when the fish transferred to long photoperiod in September had matured. They were classified into three groups: 11 non-mature males (NM), 9 mature males (MM) and 12 mature females (MF). Prior to sampling, individuals were sedated by means of bicarbonate buffered MS222 and tissue samples (intestine and kidney) were placed in RNA-later (Life Technologies, Carlsbad, CA, USA) and frozen on dry ice. For each individual fish, gender, maturation level, body weight, ovary weight, colouration and kidney weight and stage of maturation were determined. The experimental procedures were approved by the Stockholm Northern Animal Experiment Ethical Board. 


\subsection{RNA purification and first strand cDNA synthesis}

Tissues were homogenized in TRIsure (Bioline Reagents, London, UK) using a rotating knife homogenizer, and total RNA was extracted following the manufacturer's protocol. The RNA pellet was dissolved in nuclease free water and the quantity and purity (A260/A280) were estimated using a NanoDrop spectrophotometer (ND-1000, Thermo Fisher Scientific, Waltham, MA). A260/A280 was generally $>1.90$. One microgram of total RNA was converted into cDNA using the DyNAmo ${ }^{\text {TM }}$ cDNA synthesis kit from Finnzymes (Thermo Scientific, Hampton, NH, USA). First strand cDNA synthesis from $1 \mu \mathrm{g}$ total RNA was performed in a total volume of $20 \mu \mathrm{L}$ using Applied Biosystems high capacity cDNA reverse transcription kit (Foster City, CA).

\subsection{Identification of PCR targets and real-time QPCR}

Messenger RNA sequences of the following three-spined stickleback transcripts were identified in the ENSEMBL genome browser (www.ensembl.org/) and used for primer generation (see Table 1): aqpla, aqp3a, aqp8aa, aqp8ab, aqp10a, aqp10b, $\mathrm{Na}^{+}, \mathrm{Cl}^{-}$-cotransporter $(n c c), \mathrm{Na}^{+}, \mathrm{K}^{+}, 2 \mathrm{Cl}^{-}-$ cotransporter type 2 ( $n k c c 2)$ and -type 1 (nkccla and $n k c c 1 b)$, cystic fibrosis transmembrane conductance regulator $(c f t r)$, two $\mathrm{Na}^{+}, \mathrm{K}^{+}$,-ATPase alpha-1 subunit isoforms (here named $n k a 547$ and $n k a 976$ ) , claudin2, and claudin15a. A preliminary phylogenetic analysis revealed that $n k a 547$ is more similar to the trout and Japanese medaka (Oryzias latipes) alpha-1c isoforms, whereas $n k a 976$ groups phylogenetically with trout alpha- $1 a$ and $-1 b$ isoforms. Ubiquitin and $\beta$-actin were used for internal normalisation. All primers were generated using Primer3 software (Koressaar et al., 2007; Untergrasser et al., 2012). Real-time quantitative PCR was performed using a BioRad CFX96 platform (BioRad, Hercules, CA) and SYBR ${ }^{\circledR}$ Green JumpStart ${ }^{\mathrm{TM}}$ Taq ReadyMix ${ }^{\mathrm{TM}}$ (Sigma-Aldrich) in a total volume of $15 \mu \mathrm{L}$. Annealing/elongation temperature was optimized for each primer (see Table 1). Primer concentrations were $450 \mathrm{nM}$ and the thermocycling protocol consisted of $3 \mathrm{~min}$ initial denaturation $\left(94^{\circ} \mathrm{C}\right), 40$-cycles of denaturation $(15 \mathrm{~s})+$ annealing/elongation $\left(1 \mathrm{~min}, 60-69.5^{\circ} \mathrm{C}\right)$, followed by dissociation curve analysis $\left(5 \mathrm{~s} /{ }^{\circ} \mathrm{C}, 55-94\right.$ $\left.{ }^{\circ} \mathrm{C}\right)$. PCR amplification efficiency $\left(\mathrm{E}_{\mathrm{a}}, 80-105 \%\right)$ was analysed over a $2^{8}$ dilution range of a pooled cDNA sample and the relative copy numbers were calculated according to Pfaffl (2001) as: rcn = $\left(1+\mathrm{E}_{\mathrm{a}}\right)^{-\mathrm{Ct}}$, where ren is the relative copy number and $\mathrm{Ct}$ is the threshold cycle of the target gene. Corrected ren data for the two normalisation genes was entered into the geNorm software (Biogazelle, Zwijnaarde, Belgium) and a geometric mean was calculated and used for normalisation of all expression data. Contamination of RNA samples with genomic DNA was checked by running 
qPCR on randomized, diluted RNA samples ('no amplification control'). Amplification in these samples was $<2^{-8}$ of the corresponding cDNA sample. Primer-dimer association was checked in 'no template controls' without addition of cDNA. The molecular mass of all amplicons was validated by gel electrophoresis using a $2.5 \%$ SeaKem, Metaphor agarose gel (Lonza, Bazel, Switzerland); 1xTAE (40mM Tris, 20mM acetic acid,1mM EDTA), 5 V/cm, a 20 bp DNA ladder and 6x Orange Loading Dye (O’Range Ruler, Ready-to-Use; Thermo Scientific, Waltham, MA).

\subsection{Kidney and intestine morphology}

Kidney and posterior intestine was carefully dissected from one mature and one non-mature male from brackish water and fixed overnight in $4 \%$ buffered paraformaldehyde at $4{ }^{\circ} \mathrm{C}$. Following rinses in $70 \% \mathrm{EtOH}$ the tissues were dehydrated through graded series of EtOH and TissueClear@ (Sakura Finetek Europe B.V., AJ Alphen aan den Rijn, The Netherlands) and finally embedded in paraffin. Five micron thick sections were prepared using a Leitz Microtome (Leitz Microsystems, Wetzlar, Germany) and placed on Superfrost Plus microslides (Thermo Fisher Scientific, Waltham, MA, USA). Following deparaffination and rehydration, representative slides were stained using a standardized hematoxylin/eosin protocol. The stained sections were inspected using light microscopy at 20-40x magnification. Digital images were recorded and the morphology of mature vs. non-mature male tissues was compared.

\subsection{Statistical analyses}

The statistical analysis was done using the software GraphPad Prism 5 (GraphPad Software, San Diego, CA). For each target and tissue data were first analysed for equal variance using Barlett's test. If equal variance was found, a separate one-way ANOVA was used to test for differences $(\mathrm{P}<0.05)$ with respect to gender/maturity for each target in each tissue (immature female, nonmature males and mature males). Tukey's multiple comparison test was used for post-hoc testing $(\mathrm{P}<0.05)$. Where variances differed, a non-parametric one-way ANOVA was chosen using KruskalWallis test $(\mathrm{P}<0.05)$. Furthermore, in non-parametric tests, Dunn's multiple comparison test was used for post-hoc testing $(\mathrm{P}<0.05)$.

\section{Results}

\subsection{Aquaporin sequence information}


Searching the ENSEMBL genomic database revealed the presence of 16 annotated aquaporin paralogs in G. aculeatus: aqp0a, aqp0b, aqp1a, aqp1b, aqp3a, aqp4, aqp7, aqp8aa, aqp8ab, aqp8b, aqp9a, aqp9b, aqp10a, aqp10b, aqp11a and aqp12. Six of these were selected for further transcript analyses: aqp1a, aqp3a, aqp8aa, aqp8ab, aqp10a and aqp10b, based on our previous experience with these as being the main paralogs expressed in kidney and intestine tissues (Tingaud-Sequeira et al., 2010; Tipsmark et al., 2010b; Madsen et al., 2014). All identified Aqp protein sequences grouped with the expected orthologs in other teleosts as shown in Tingaud-Sequeira et al. (2010).

\subsection{Transcript tissue distribution}

Our tissue screening analysis (Fig. 2) revealed that aqpla was predominantly expressed in liver, brain, kidney and intestine; aqp3a was at highest level in the esophagus and also detected at lower levels in all other tissues. Aqp8aa was a predominant intestinal paralog expressed at $>100$-fold higher levels in the intestine than in any other organ. aqp $8 a b$ was expressed at high levels in both intestine and kidney. Aqp10a was expressed in all tissues except gonad. Aqp10b was predominantly expressed in the intestine and kidney, and low in all other studied tissues.

$C l d n 2$ was primarily expressed in liver and gill tissue but was also present at low levels in all other tissues (Fig. 3A). In contrast cldn15a was highly expressed in the two intestinal segments and only present at very low levels in all other tissues (Fig. 3B). Nkccla was significantly expressed in all tissues examined with the highest mRNA level in gills (Fig. 3C). $N k c c 2$ was almost exclusively expressed and at similar levels in the intestinal and kidney tissues (Fig. 3D). Ncc was abundant in kidney and present at much lower levels in all other tissues. Cftr was present at several-fold higher level in the intestine and gill than any other tissue (Fig. 3E). Nka547 and $n k a 976$ were expressed in all tissues, though with great differences. The major difference in the expression profile of these isoforms was the high level of $n k a 547$ in the brain whereas $n k a 976$ was close to the detection level.

\subsection{Kidney and intestine morphology}

There was a clear difference in morphology of kidney tubules between sexually mature and nonmature males (Fig. 4). In the MM tubular cells were hypertrophied and the relative lumen diameter was much smaller than compared to non-mature individuals. Nuclei of the MM tubule cells were located basally in the cells, whereas in the NM nuclei were located centrally. On the other hand, at the light microscopic level, there was no obvious difference in the morphology of the intestine and enterocytes between the two stages (Fig. 5). 


\subsection{Sexual maturation and expression levels}

Spiggin mRNA (Fig. 6) was highly expressed in the kidney of MM and present at very low levels in $\mathrm{NM}$ and MF. In the intestine the spiggin mRNA level was near the detection limit. The mRNA level of the analyzed aquaporins varied widely between tissue and gender/stage (Fig. 7A-F). Aqpla was slightly higher in the intestine of MM than of MF, and it was lower in the kidney of MM than in NM. The aqp3a level was many times higher in the intestine of MF than of both NM and MM and $>10$-fold higher in the kidney of MM than in both MF and NM. The aqp8aa level was higher in the intestine of MM than MF, whereas levels in MM and NM were similar. The aqp8ab paralog was expressed at lower level in the intestine of MF than in NM. In the kidney, aqp8ab was lower in MM than in both MF and NM. Aqp10a levels were unaffected by gender and stage in both kidney and intestine, whereas intestinal $a q p 10 b$ was higher in NM and MM compared to MF, and the kidney transcript level was similar in MF, NM and MM.

Overall, there was no significant difference in $c l d n 2$ expression level between gender/stage (Fig. 8A). Cldn15a was expressed at similar level in the intestine of MF, NM and MM, whereas in the kidney, NM had a lower level than both MF and MM (Fig. 8B). The intestinal $n k c c l a$ mRNA level was unaffected by gender/stage, and the kidney level was strongly up-regulated in the MM compared to MF and NM (Fig. 8C). The intestinal $n k c c 2$ mRNA level was lower in MM than in MF and NM. There was no difference between groups in the kidney levels of this transcript (Fig. 8D). The intestinal $n c c$ level was similar in the intestines of the three groups but was significantly lower in the kidney of MM compared to the kidney of MF (Fig. 8E). Cftr, nka547 and nka976 were present at higher level in the intestine of MF compared to their NM counterparts (Fig. 8F-H), whereas kidney levels of these three transcripts were unaffected by stage/gender.

\section{Discussion}

As androgen levels rise, the kidney of maturing stickleback males gradually turns into a protein secretory organ (De Ruiter and Mein, 1982), which leads to a strongly compromised role as a water secreting organ (De Ruiter, 1980a). There are physiological indications from a single experiment showing that as the osmoregulatory function of the kidney regresses the intestine develops a compensatory capacity to secrete hypotonic fluid (De Ruiter, 1980b, De Ruiter and Wendelaar Bonga, 1985). According to the backward channel standing gradient osmotic flow model of the intestine (Diamond and Bossert, 1967, 1968; De Ruiter 1980b) osmotic water secretion needs salt to 
be secreted to the mucosal side, which obviously is not compatible with apical $\mathrm{NaCl}$ absorption in the same location. De Ruiter argued that salt- and water transport most likely was transcellular from serosa to mucosa, since tight junctions were present between cells. At that time, however, the diverse properties of tight junctions were not known, as will be discussed later. In our working model of hypotonic fluid secretion (Fig. 1), we propose that $\mathrm{Na}^{+}$secretion occurs via paracellular leakage of $\mathrm{Na}^{+}$driven by the basolateral $\mathrm{Na}^{+}, \mathrm{K}^{+}$-ATPase in conjunction with transcellular exit of $\mathrm{Cl}^{-}$ through apical cystic fibrosis transmembrane conductance regulator (CFTR) $\mathrm{Cl}^{-}$-channels, similar to the present models for salt secretion in the mammalian ileum (Field, 2003). Water may then follow via a transcellular route through aquaporins and/or a paracellular route through tight junctions. By comparison, the pathophysiological condition of diarrhea in mammals induced by cholera toxin is due to a combination of stimulated $\mathrm{NaCl}$ secretion and reduced $\mathrm{NaCl}$ absorption (Hodges and Gill, 2010). At the same time there is presumably a reduction in transcellular water permeability caused by down-regulation of AQP3 and an increase in the paracellular water permeability caused by modifications of the tight junction apparatus (Guttman and Finlay, 2008). The secreted fluid will be expected to be isotonic with serosal fluid, and in order not to lose excessive amounts of $\mathrm{NaCl}$ by this mechanism in a FW scenario, it is imperative to reabsorb $\mathrm{NaCl}$ further along the distal part of the intestine. Thus, there needs to be segmental expression of various ion transporters along the intestine. De Ruiter (1980b) indeed found that the secreted fluid from the intestine of MM was hypotonic to blood and argued that there must be $\mathrm{NaCl}$ reabsorption taking place somewhere along the distal intestine. He found support for this idea in ultrastructural differences between anterior and posterior regions of the intestine. Based on this structural and functional re-modelling there is good reason to expect several changes in the molecular apparatus that is involved in water and salt transport across the epithelial layers in intestine and kidney. The present study confirmed at the transcript level that gender and stage-specific differences indeed exist in several molecular components, which may contribute to defining the water and solute transport properties of the kidney and intestine. Changes in protein levels and post-translational modifications may occur independently to this and thus add additional aspects to the physiological regulation, which were outside the scope of this investigation.

\subsection{Kidney and intestine morphology}

When analyzing the renal morphology, the tubular cells in the MM appeared much hypertrophied compared to the tubules of the NM. This is in line with earlier studies in different stickleback 
species (e.g. Hess, 1918; De Ruiter and Wendelaar-Bonga, 1985) and most likely associated with the de novo synthesis of the spiggin protein, which is secreted and used for nest-building. Spiggin mRNA levels clearly supported this, since MM had $>10^{6}$-fold higher mRNA level compared to NM and MF. By comparison, spiggin mRNA was just about the detection level in the intestine of the three groups. The lack of obvious difference in intestinal morphology between NM and MM was surprising considering the paper by De Ruiter et al. (1985) who reported (at the electron microscopic level) formation of basal membrane labyrinths in the posterior intestine of $\mathrm{MM}$. We may, however, have missed such changes by analyzing at the light microscopic level.

\subsection{Transcript levels of aquaporins in intestine and kidney.}

Six aquaporin paralogs were selected for analysis at the transcript level: aqpla, aqp8aa, aqp8ab, aqp3a, aqp10a and aqp10b. The three former are considered as true water pores, whereas the latter three are usually referred to as aquaglyceropores, due to their additional permeability to glycerol (Cerdá and Finn, 2010). The sequences of these paralogs all grouped with their corresponding paralogs in other teleost species in the extensive phylogenetic analysis made by Tingaud-Sequeira et al. (2010), thereby validating the annotation used in ENSEMBL. All paralogs were expressed in the kidney and intestine of sticklebacks though at variable levels. Especially aqp8aa, aqp8ab and $a q p 10 b$ were relatively highly expressed in the intestine and $a q p 8 a b$ and $a q p 10 b$ also in the kidney. Aqp3a was predominantly expressed in the esophagus and aqpla and aqp10a were expressed at intermediate-to-low levels in most tissues. Thus assuming that these transcripts are translated into functional proteins, the basis for transmembrane and maybe transepithelial water transport seems to be present in both intestine and kidney. Overall the tissue profiles are in accordance with the expression profiles of these paralogs in zebrafish, where especially aqp8aa, aqp8ab, aqp10a and $a q p 10 b$ are relatively strongly expressed in intestine and kidney (Tingaud-Sequeira et al., 2010). When comparing the intestinal aquaporin transcript level between gender/stage, several paralogs showed a gender-specific difference - not related to sexual development in the males. Aqpla, aqp8aa and aqp10b were all higher in MM than in MF and aqp3a was reduced in MM compared to MF. None of these aquaporins were expressed at different levels in NM and MM, which would be expected in connection with the re-modelling of the intestine into a water secretory organ. De Ruiter's (1980b) measurement of higher osmotic water permeability of intestines of MM compared to NM is thus not supported by our analysis of aquaporin mRNA expression. Water permeability 
may, however, also be strongly affected by the paracellular component created by the protein interactions in the intercellular junctional apparatus as discussed below.

In contrast to the intestine, there were stage-specific changes in renal aquaporin expression between $\mathrm{NM}$ and MM but no gender-specific differences: aqpla and aqp8ab were lower in MM than in NM and aqp3a was much elevated in MM compared to NM. These differences may be related to the major transformation of the kidney from an uriniparous kidney into a kidney secreting spiggin in the maturing males. The opposite directions of the observed changes suggests that the strong upregulation of aqp3a may either be a compensation for the down-regulation of aqpla and aqp8ab, and/or that there may be regional differences between the tubule segments: e.g. reduced aqpla and $a q p 8 a b$ expression may lead to reduced water permeability of the proximal part of the nephron, whereas aqp3a may be involved in water secretion in the more distal parts in order to support the flow of the proteinaceous fluid containing spiggin. The stickleback kidney only contains proximal (I and II) and collecting tubule segments, and De Ruiter and Wendelaar-Bonga (1985) emphasized, that the transformation into a secretory epithelium took place in the 2 nd proximal and the collecting tubule segments only and not in the 1st proximal segment, which comprised only about $10 \%$ of the whole nephron. Ultrastructural examination showed that the 2 nd proximal segment turned into a serous (granular) epithelium, whereas the hypertrophied collecting tubules more resembled a mucous secreting epithelium with different histochemical staining properties (De Ruiter and Mein, 1982; De Ruiter and Wendelaar-Bonga, 1985). Thus a regionalization of the response is very likely to occur similar to the regionalization of the androgen response (De Ruiter and Mein, 1982). The Aqp3a protein was recently reported in the apical region of renal proximal tubules in the Atlantic salmon (Salmo salar; Engelund and Madsen, 2015), whereas the Aqp3b paralog has been reported in mucus cells of the esophagous and posterior regions of the European eel (Anguilla anguilla) intestine and also in apical regions of renal tubular cells (Cutler et al., 2007). In frogs, Aqp3 is expressed at the basolateral membrane of collecting ducts and late distal tubules (African clawed frog, Xenopus laevis: Mochida et al., 2008; Cope's gray treefrog, Hyla chrysoscelis: Pandey et al., 2010) as well as in secretory cells in the small granular and mucous glands of the skin. In mammals, AQP3 is localized in many tissues and cell types including secretory salivary acinar cells (Gresz et al., 2001). De Ruiter and Wendelaar-Bonga (1985) also described the ultrastructure of collecting tubule cells in the MM as being similar to mucus secreting cells, filled with secretory granules so high aqp3 expression in these cells is likely to occur. However, a firmer conclusion about the functional roles of these changes will have to await protein localization studies. 


\subsection{Transcript levels of ion-transporting proteins.}

The present mRNA tissue profiles were based on pooled data from immature males and females from brackish salinity and we generally did not find any differentiation of transcript levels with regard to gender (not shown). Salinity may influence the level of some of the targets in the osmoregulatory tissues but this effect was beyond the scope of this study. Thus the purpose of the tissue profiles merely was to assure that the chosen transcripts were relevant targets for a closer examination in intestine and kidney. Our analytical approach aimed to validate the hypothetical model shown in Figure 1. We found it reasonable to propose that secretion of a hypotonic fluid from the intestine most likely involves several ion-transporting components in addition to specific trans- or paracellular pathways for water transport. Our data generally confirmed expression at the mRNA level of two isoforms of $\mathrm{Na}^{+}, \mathrm{K}^{+}$-ATPase ( $n k a 547$ and $\left.n k a 976\right), n k c c 1 a, n k c c 2, n c c$ and $c f t r$ in the intestine. The tissue profiles revealed that $n k a 976$ has a more versatile distribution than nka547, which by far had the highest transcript level in the brain. Despite some uncertainty, we were surprised that a preliminary phylogenetic analysis revealed that $n k a 547$ is more similar to the trout and Japanese medaka alpha- $1 c$ isoforms, whereas $n k a 976$ groups phylogenetically with trout alpha- $1 a$ and $-1 b$ isoforms (S. Madsen, unpublished data). In salmonids, alpha- $1 c$ is the predominant alpha subunit in the intestine (Tipsmark et al., 2010a, Sundh et al., 2014) but this seems not to be the case in stickleback. Thus the basic apparatus for both ion absorption ( $n k a$, $n k c c 2, n c c)$ and secretion $(n k a, n k c c l a, c f t r)$ is present even though we did not find any evidence of a segmental organization of these transcripts, which would be expected according to our model. Intestinal $\mathrm{NaCl}$ absorption is a process which has been described in many studies (e.g. Sundh et al., 2014), whereas $\mathrm{NaCl}$ secretion has been speculated (Cutler and Cramb, 2002) and documented only in a few studies (killifish: Marshall et al., 2002; Gulf toadfish: Ruhr et al., 2014).

There were gender specific differences in the intestinal mRNA level of the two $n k a$ isoforms and $c f t r$, with MF having higher levels than NM. There were, however, no stage-specific differences in the levels of these three targets which we could relate to male-maturation. The secretory $n k c c l a$ cotransporter (solute carrier family 12 member 2, Slc12a2) mRNA was expressed in a wide range of tissues including kidney and intestine. The level here was lower than in the gill, which agrees with this isoforms distribution in the eel (Cutler and Cramb, 2002). The presence of the $n k c c l a$ isoform strongly suggests a pathway for salt secretion in these tissues, which may be involved in the secretion of fluid. In the intestine there was no difference between genders or stages, so it seems to 
be a general mechanism rather than a particular feature developing during male maturation. Cutler and Cramb (2002) found no difference in intestinal $n k c c l a$ mRNA levels between FW and SWacclimated or yellow and silver eels, suggesting that this mechanism is present irrespective of both salinity and development. There was a significant up-regulation of $n k c c l a$ in the kidney of MM sticklebacks compared to both MF and NM, which may be involved in salt (and fluid) secretion to support the flow of spiggin through the kidney tubules.

The absorptive-type $n k c c 2$ cotransporter (solute carrier family 12 member 1, Slc2a1), was expressed in intestine and kidney at distinctly higher levels than in all other tissues. In mammals this was originally found to be a kidney specific isoform (Lytle et al., 1995) but has later been found in kidney tubules as well as apical membrane of enterocytes of both mammals and fish (rat, Rattus norvegicus: Xue et al. 2009; European eel: Cutler and Cramb, 2008; olive flounder, Paralichythys olivaceus: Kim et al., 2013; Japanese medaka: Madsen et al., 2014), where it is involved in $\mathrm{NaCl}$ absorption/re-absorption (Grossel, 2011). The $n k c c 2$ mRNA level was unaffected by gender/stage in the kidney but interestingly, the level was significantly lower in the intestine of MM than in NM and MF, suggesting that the intestinal ion absorption capacity is somehow reduced in MM compared to the non-mature males and the mature females. This seems opposite to what would be expected according to the proposed model. The NKCC 2 in the intestine is known to be an important component associated with absorption of imbibed seawater in marine teleosts (Grossel, 2011) and is up-regulated in euryhaline fish during seawater acclimation (Madsen et al., 2014). Thus the downregulation of $n k c c 2$ in the MM may be interpreted as a down-regulation of the fluid-absorption potential which does neither support or conflict with the concept that the intestine is transformed into a water secretory organ (De Ruiter and Wendelaar-Bonga, 1985).

By comparison, the $n c c$ cotransporter (solute carrier family 12 member 3, Slc12a3), also known as the thiazide-sensitive $\mathrm{NaCl}$ cotransporter, was expressed at high level in the kidney whereas the transcript level was close to the detection level in the anterior and posterior segments of the intestine. The intestinal mRNA level was unaffected by gender/stage but the level in the kidney was lower in MM compared to MF but similar to NM. The NCC may potentially contribute to ion absorption in the intestine of SW teleosts (Grossell, 2011) and in the re-absorption of $\mathrm{NaCl}$ in distal tubules of the kidney of FW teleosts (Kato et al., 2011) as well as mammals (Reilly and Ellison, 2000). It was reported absent, however, in the intestine of FW tilapia larvae (Oreochromis mossambicus, Hiroi et al., 2008). Cutler and Cramb (2008) found two isoforms of NCC expressed at the mRNA level in eel: an $\alpha$ isoform which was only present in kidney tissue and a $\beta$ isoform 
which was abundant in posterior intestine but absent in the anterior segment. In stickleback we identified one isoform of the ncc in the ENSEMBL database and it is somewhat surprising that this is expressed at high levels in the kidney, which lacks the distal tubules typical of FW teleosts (Hess, 1918; De Ruiter and Wendelaar Bonga, 1985). We speculate that the re-absorptive capacity is most likely present in the collecting tubules which may act as a diluting segment. The lower $n c c$ mRNA level in the MM compared to MF may lead to a lower re-absorptive capacity in the strongly compromised kidney, which also has a lower urine flow.

\subsection{Claudin expression}

Epithelial water permeability is defined by the combined properties of trans- and para-cellular components. Aquaporins comprise the main trans-cellular leak and the tight junction apparatus may form leaky as well as tight connections between cells. Most studies today have focused on the electrical properties of tight junctions and it is well-known that specific claudin isoforms may create ionic barriers or anionic as well as cationic leaky pathways (Angelow et al., 2008; Hou et al., 2013). A few claudins have also been suggested to create water permeable pores, and the general permeability properties are largely defined by the biophysical properties of the approximately 50 amino acids of the first extracellular loop since this region is believed to form a lining of the paracellular pore. Sequence alignment of this region from different isoforms may thus give clues about the physical properties in other species. As seen in Table 2, there are obvious similarities in the biophysical properties of the first extracellular loop amino acid sequence between human claudin 2 and 15, respectively and their corresponding fish orthologs. Thus similar properties could be expected among these orthologs. Claudin 2, which is typical of water leaky epithelia in mammals, has been shown to increase paracellular water permeability when expressed in MadinDarby canine kidney (MDCK) cell monolayers (Rosenthal et al., 2010). In stickleback claudin2 was expressed at very low levels in both kidney and intestine, and the levels were no different in the mature male group. Thus claudin 2 most likely does not make a significant contribution to water permeability in the stickleback intestine and kidney.

The other claudin isoforms analyzed, $\operatorname{cldn} 15 a$, seemed to be more specific to the intestine, which is in agreement with other studies (D. rerio: Bagnat et al., 2007; S. salar: Tipsmark et al., 2010b). The lack of expression of $c l d n 15 a$ in the esophagus suggests that other isoforms may be significant in this section and also emphasize the particular character when compared to posterior segments. It has been shown that this isoform is cation selective in mammals (Colegio et al., 2002) and based on the 
structural similarity of the first extracellular loop of stickleback Claudin 15 with mammalian Claudin15 and zebrafish Claudin15, it is obvious to speculate that this claudin forms cationselective pores that may contribute to transepithelial ion movement in the direction of the actual electrochemical gradient. Even though the water permeability properties of this pore remain to be demonstrated directly, it was indicated from a study of gut ontogeny in zebrafish (Bagnat et al., 2007), where knock-down of this isoform during early development prevented gut lumen formation which involves osmotic swelling of the endodermal rod in the wild type. In the present study, claudin15a expression did not vary between gender/stage in the intestine; however, in the kidney the MM group had higher expression than the NM group, suggesting altered permeability properties of the kidney tubules when spiggin-secretion is induced.

\subsection{Conclusion}

The present study identified organ-specific differences in the expression profiles of ion- and water transport components that were related to sexual maturation in males. In the kidney, differences in aquaporin expression as well as $n k c c l a, n c c$ and $c l d n 15 a$ expression suggested increased water permeability and salt secretion which may facilitate spiggin secretion in a condition where glomerular filtration rate is reduced (De Ruiter, 1980b). In the intestine, the changes were more subtle, and the major difference between MM and NM was the reduced expression of $n k c c 2$, which may facilitate a switch to a salt/water secretory mode rather than a salt-absorptive mode of the intestine. We did not find evidence supporting the hypothesis of increased transcellular water permeability as proposed by De Ruiter. Our data therefore lead us to speculate that a modification of the paracellular component may be of primary importance, when the intestine is transformed into a water secretory organ during male maturation. In order to further clarify the mechanisms of this fascinating physiological transformation more targets as well as their segmental organization in the intestine must be investigated.

\section{Acknowledgements.}

Annette Duus is thanked for skillful technical assistance with preparation of the histology preparations. The study was supported by a grant from the Danish Research Council for Independent Research to SSM (09-070689) and by a grant from the National Science Foundation (IBN 12-51616) to CKT. 


\section{References}

Angelow, S., Ahlstrom, R., Yu, A.S.L. 2008. Biology of claudins. Am. J. Physiol. (Renal Physiol.) 295, R867-876.

Bagnat, M., Cheung, I.D., Mostov, K.E., Stainier, D.Y.R. 2007. Genetic control of single lumen formation in the zebrafish gut. Nature Cell Biology 9, 954-960.

Borg, B., Antonopoulou, E., Andersson, E., Carlberg, T., Mayer, I. 1993. Effectiveness of several androgens in stimulating kidney hypertrophy, a secondary sexual character, in castrated male three-spined sticklebacks, Gasterosteus aculeatus. Can. J. Zool. 71, 2327-2329.

Cerdá, J., Finn, R.N. 2010. Piscine aquaporins: an overview of recent advances. J. Exp. Zool. 313A, 623-650.

Colegio, O.R., Van Itallie, C.M., McCrea, H.J., Rahner, C., Anderson, J.M. 2002. Claudins create charge-selective channels in the paracellular pathway between epithelial cells. Am. J. Physiol. (Cell Physiol.) 283, C142-147.

Cutler, C.P., Cramb, G. 2002. Two isoforms of the $\mathrm{Na}^{+} / \mathrm{K}^{+} 2 \mathrm{Cl}$ - cotransporter are expressed in the European eel (Anguiilla anguilla). Biochim. Biophys. Acta 1566, 92-103.

Cutler, C.P., Cramb, G. 2008. Differential expression of absorptive cation-chloride-cotransporters in the intestinal and renal tissues of the European eel (Anguilla anguilla). Comp. Biochem. Physiol. 149B, 63-73.

Cutler, C.P., Martinez, A.S., Cramb, G. 2007. The role of aquaporin 3 in teleost fish. Comp. Biochem. Physiol. 148A, 82-91.

De Ruiter, A.J.H. 1980a. Changes in glomerular structure after sexual maturation and seawater adaptation in males of the euryhaline teleost Gasterosteus aculeatus L. Cell Tissue Res. 206, 120.

De Ruiter, A.J.H. 1980b. Effects of testosterone on kidney structure and hydromineral regulation in the teleost Gasterosteus aculeatus L. Ph.D. thesis, State Univ. Groningen, The Netherlands.

De Ruiter, A.J.H., Hoogeveen, Y.L., Wendelaar Bonga, S.E. 1985. Ultrastructure of intestinal and gall-bladder epithelium in the teleost Gasterosteus aculeatus L., as related to their osmoregulatory function. Cell Tissue Res. 240, 191-198.

De Ruiter, A.J.H., Mein, C.G. 1982. Testosterone-dependent transformation of nephronic tubule cells into serous and mucous gland cells in stickleback kidneys in vivo and in vitro. Gen. Comp. Endocrinol. 47, 70-83. 
De Ruiter A.J.H., Wendelaar Bonga, S.E. 1985. Consequences of nestbuilding behaviour for osmoregulation in male three-spined stickleback. Behaviour 93, 8-20.

Devore, D.P., Engebretson, G.H., Schachtele, C.F., Sauk, J. J. 1984. Identification of collagen from byssus threads produced by the sea mussel, Mytilus edulis. Comp. Biochem. Physiol. 77B, 529532.

Diamond, J.M., Bossert, W.H. 1967. Standing gradient osmotic flow: a mechanism for coupling of water and solute transport in epithelia. J. Gen. Physiol. 50, 2061-2083.

Diamond, J.M., Bossert, W.H. 1968. Functional consequences of ultrastructural geometry in 'backwards' fluid-transporting epithelia. J. Cell Biol. 37, 694-702.

Edwards, S., Marshall, W.S. 2013. Principles and patterns of osmoregulation and euryhalinity in fishes. In: McCormick, S.D., Farrell, A.P., Brauner, C.J. (Eds.), Fish Physiology, vol. 32, Academic Press, New York, pp. 1-44.

Engelund, M.B., Madsen, S.S. 2015. Tubular localization and expressional dynamics of aquaporins in the kidney of seawater challenged Atlantic salmon. J. Comp. Physiol. 185, 207-223.

Field, M. 2003. Intestinal ion transport and the pathophysiology of diarrhea. J. Clin. Invest. 111, 931-943.

Gosline, J.M., Guerette, P.A., Ortlepp, C.S., Savage, K.N. 1999. The mechanical design of spider silks: from fibroin sequence to mechanical function. J. Exp. Biol. 202, 3295-3303.

Gresz, V., Kwon, T.H., Hurley, P.T., Varga, G., Zelles, T., Nielsen, S., Case, R.M., Steward, M.C. 2001. Identification and localization of aquaporin water channels in human salivary glands. Am. J. Physiol. (Gastrointest Liver Physiol.) 281, G247-254.

Grossel, M. 2011. Intestinal anion exchange in marine teleosts is involved in osmoregulation and contributes to the oceanic inorganic carbon cycle. Acta Physiol. 202, 421-434.

Guttman, J.A., Finlay, B.B. 2008. Subcellular alterations that lead to diarrhea during bacterial pathogenesis. Trends in Microbiology 16, 535-542.

Hess, W.N. 1918. A seasonal study of the kidney of the five-spined stickleback, Eucalia inconstans Cayuga Jordan. Anat. Rec. 14, 141-163.

Hiroi, J., Yasumasu, S., McCormick, S.D., Hwang, P.-P., Kaneko, T. 2008. Evidence for an apical $\mathrm{Na}-\mathrm{Cl}$ cotransporter involved in ion uptake in a teleost fish. J. Exp. Biol. 211, 2584-2599.

Hodges, K., Gill, R. 2010. Infectious diarrhea. Cellular and molecular mechanisms. Gut Microbes 1, 4-21. 
Hou, J., Rajagopal, M., Yu, A.S.L. 2013. Claudins and the kidney. Annu. Rev. Physiol. 75, 479501.

Jakobsson, S., Borg, B., Haux, C., Hyllner, S.J. 1999. An 11-ketotestosterone induced kidneysecreted protein: the nest building glue from male three-spined stickeback, Gasterosteus aculeatus. Fish Physiol. Biochem. 20, 79-85.

Jones, I., Lindberg, C., Jakobsson, S., Hellman, U., Hellqvist, A., Borg, B., Olsson, P.-E. 2001. Molecular cloning and characterization of spiggin: an androgen regulated extraorganismal adhesive with structural similarities to von Willebrand Factor -related proteins. J. Biol. Chem. 276, 17857-17863.

Kato, A., Muro, T., Kimura, Y., Li, S., Islam, Z., Ogoshi, M., Doi, H., Hirose, S. 2011. Differential expression of $\mathrm{Na}-\mathrm{Cl}$ cotransporter and $\mathrm{Na}-\mathrm{K}-\mathrm{Cl}$ cotransporter 2 in the distal nephrons of euryhaline and seawater pufferfishes. Am. J. Physiol. (Regul. Integr. Comp. Physiol.) 300, R284-R297.

Kim, Y.K., Watanabe, S., Park, S.I., Jeong, J.B., Kaneko, T., Park, M.A., Yeo, I.K. 2013. Molecular characterization and gene expression of $\mathrm{Na}^{+}-\mathrm{K}^{+}-2 \mathrm{Cl}^{-}$cotransporter2 $(\mathrm{NKCC} 2)$ in the gastrointestinal tract of Olive flounder (Paralichythys olivaceus) during the four days after infection with Streptococcus parauberis. Mar. Fresh. Behav. Physiol. 46, 145-157.

Koressaar, T., Remm, M. 2007. Enhancements and modifications of primer design program Primer3. Bioinformatics 23, 1289-1291.

Lytle, C., Xu, J.C., Biemesderfer, D., Forbush, B. 1995. Distribution and diversity of Na-K-Cl cotransport proteins: a study with monoclonal antibodies. Am. J. Physiol. (Cell Physiol.) 269, C1496-1505.

Madsen, S.S., Olesen, J.H., Bedal, K., Engelund, M.B., Velasco-Santamaría, Y., Tipsmark, C.K. 2011. Functional characterization of water transport and cellular localization of three aquaporin paralogs in the salmonid intestine. Front. Physiol. 2, 56.

Madsen, S.S., Bujak, J., Tipsmark, C.K. 2014. Aquaporin expression in the Japanese medaka (Oryzias latipes) in freshwater and seawater: challenging the paradigm of intestinal water transport? J. Exp. Biol. 217, 3108-3121.

Marshall, W.S., Howard, J.A., Cozzi, R.R.F., Lynch, E.M. 2002. NaCl and fluid secretion by the intestine of the teleost Fundulus heteroclitus: involvement of CFTR. J. Exp. Biol. 205, 745-758. 
Mochida, H., Nakakura, T., Suzuki, M., Hayashi, H., Kikuyama, S., Tanaka, S. 2008. Immunolocalization of a mammalian aquaporin 3 homolog in water-transporting epithelial cells in several organs of the clawed toad Xenopus laevis. Cell Tissue Res. 333, 297-309.

Mondal, M., Trivedy, K., Nirmal Kumar, S. 2007. The silk proteins, sericin and fibroin in silkworm, Bombyx mori Linn., - a review. Caspian J. Env. Sci. 5, 63-76.

Möbius, K. 1885. Über die Eigenschaften und den Ursprung der Schleimfäden des Seestichlingsnestes. Arch. mikr. Anat. 25, 554-563.

Pandey, R.N., Yaganti, S., Coffey, S., Frisbie, J., Alnajjar, K., Goldstein, D. 2010. Expression and immunolocalization of aquaporins HC-1, -2, and -3 in Cope's gray treefrog, Hyla chrysoscelis Comp. Biochem. Physiol. 157A, 86-94.

Pfaffl, M.W. 2001. A new mathematical model for relative quantification in real-time RT-PCR. Nucleic Acids Res. 29, e45.

Reilly, R.F., Ellison, D.H. 2000. Mammalian distal tubule: physiology, pathophysiology, and molecular anatomy. Physiol. Rev. 80, 277-313.

Rosenthal, R., Milatz, S., Krug, S.M., Oelrich, B. Schulzke, J.-D., Amasheh, S., Günzel, D., Fromm, M. 2010. Claudin-2, a component of the tight junction, forms a paracellular water channel. J. Cell Science 123, 1913-1921.

Ruhr, I.M., Bodinier, C., Mager, E.M., Esbaugh, A.J., Williams, C., Takei, Y., Grosell, M. 2014. Guanylin peptides regulate electrolyte and fluid transport in the Gulf toadfish (Opsanus beta) posterior intestine. Am. J. Physiol. (Reg. Integr. Comp. Physiol.) 307,, R1167-R1179.

Sundh, H., Nilsen, T.O., Lindström, J., Hasselberg-Frank, L., Stefansson, S.O., McCormick, S.D., Sundell, K. 2014. Development of intestinal ion-transporting mechanisms during smoltification and seawater acclimation in Atlantic salmon, Salmo salar. J. Fish Biol. 85, 1227-1252.

Tingaud-Sequeira, A., Calusinska, M., Finn, R.N., Chauvigné, F., Lozano, J., Cerdá, J. 2010. The zebrafish genome encodes the largest vertebrate repertoire of functional aquaporins with dual paralogy and substrate specificities similar to mammals. BMC Evol. Biol. 10, 38

Tipsmark, C.K., Sorensen, K.J., Hulgard, K., Madsen, S.S. 2010a. Claudin-15 and-25b expression in the intestinal tract of Atlantic salmon in response to seawater acclimation, smoltification and hormone treatment. Comp. Biochem. Physiol. 155A, 361-370.

Tipsmark, C.K., Sørensen, K.J., Madsen, S.S. 2010b. Aquaporin expression dynamics in osmoregulatory tissues of Atlantic salmon during smoltification and seawater acclimation. J. Exp. Biol. 213, 368-379. 
Tsuda, M., Ohshima, Y., Suzuki, Y. 1979. Assumed initiation site of fibroin gene transcription. Proc. Natl. Acad. Sci. U. S. A. 76, 4872-4876.

Xue, H., Liu, S., Ji, T., Ren, W., Zhang, X.H., Zheng, L.F., Wood, J.D., Zhu, J.X. 2009. Expression of NKCC2 in the rat gastrointestinal tract. Neurogastroenterol. Motil. 21, 1068-e89.

Untergrasser, A., Cutcutache, I., Koressaar, T., Ye, J., Faircloth, B.C., Remm, M., Rozen, S.G. 2012. Primer3 - new capabilities and interfaces. Nucleic Acids Res. 40, e115. 


\section{Figure legends}

Figure 1. Hypothetical working model of hypotonic fluid secretion in the intestine of mature male stickleback. Isotonic fluid is secreted in the anterior section of the intestine (A): salt secretion driven by basolateral $\mathrm{Na}^{+}, \mathrm{K}^{+}$-ATPase and mediated by basolateral $\mathrm{Na}^{+}, \mathrm{K}^{+}, 2 \mathrm{Cl}^{-}$-cotransport, apical chloride channels (CFTR) and paracellular $\mathrm{Na}^{+}$leakage, creates a solute gradient, which drives osmotic movement of water through aquaporins and/or paracellular leakage (B). Hypotonicity is obtained in the (water tight) posterior section (A) by absorbing salt driven by basolateral $\mathrm{Na}^{+}, \mathrm{K}^{+}-$ ATPase in combination with apical $\mathrm{Na}^{+}\left(, \mathrm{K}^{+}\right), \mathrm{Cl}^{-}$-cotransport and basolateral chloride channels $(\mathrm{C})$.

Figure 2. Transcript levels of apq1a, aqp3a, aqp8aa, aqp8ab, aqp10a and aqp10b in various tissues from brackish water $G$. aculeatus. Shared letters above bars mean not significantly different. mRNA levels were normalized to the geometric mean of ubiquitin and $\beta$-actin mRNA levels.

Figure 3. Transcript levels of claudin2 (A), claudin15a (B), nkcc1a (C), nkcc2 (D), ncc2 (E), cftr (F), nka547 (G) and $n k a 976(\mathrm{H})$ in various tissues from brackish water G. aculeatus. Shared letters above bars mean not significantly different. mRNA levels were normalized to the geometric mean of ubiquitin and $\beta$-actin mRNA levels.

Figure 4. Representative light micrographs showing $5 \mu \mathrm{m}$ sections of hematoxylin-eosin stained kidney from mature G. aculeatus males (A,B) and non-mature males (C,D). Scale bar is $100 \mu \mathrm{m}$. Kidney tubule cells are clearly hypertrophied with basally located nuclei (arrows) in the mature male kidney.

Figure 5. Representative light micrographs showing $5 \mu \mathrm{m}$ sections of hematoxylin-eosin stained posterior intestine from mature G. aculeatus males (A) and non-mature males (B). Scale bar is $100 \mu \mathrm{m}$. No obvious difference is seen between the two stages.

Figure 6. Transcript levels of spiggin in intestine and kidney from G. aculeatus. Fish were kept in freshwater and categorized as mature females $(\mathrm{MF})$, non-mature males $(\mathrm{NM})$ or mature males (MM). Mean values of a given transcript were compared only within tissues, where shared letters 
above bars mean not significantly different. mRNA levels were normalized to the geometric mean of ubiquitin and $\beta$-actin mRNA levels.

Figure 7. Transcript levels of apq1a, aqp3a, aqp8aa, aqp8ab, aqp10a and aqp10b in intestine and kidney from $G$. aculeatus. Fish were kept in freshwater and categorized as mature females $(\mathrm{MF})$, non-mature males (NM) or mature males (MM). Mean values of a given transcript were compared only within tissues where shared letters above bars mean not significantly different. mRNA levels were normalized to the geometric mean of ubiquitin and $\beta$-actin mRNA levels.

Figure 8. Transcript levels of claudin2 (A), claudin15a (B), nkcc1a (C), nkcc2 (D), ncc2 (E), cftr (F), nka547 (G) and nka976 (H) in intestine and kidney from G. aculeatus. Fish were kept in freshwater and categorized as mature females (MF), non-mature males (NM) or mature males (MM). Mean values of a given transcript were compared within tissues only, where shared letters above bars mean not significantly different. mRNA levels were normalized to the geometric mean of ubiquitin and $\beta$-actin mRNA levels. 
Table 1. Primer sequences, annealing/elongation temperature, expected amplicon size, amplification efficiency and ENSEMBLE transcript ID number of the selected targets and normalization genes from G. aculeatus.

\begin{tabular}{|c|c|c|c|c|c|}
\hline target & primer sequences & $\begin{array}{c}\text { anneal/ } \\
\text { elong } \\
\text { temp. }\left({ }^{\circ} \mathrm{C}\right)\end{array}$ & $\begin{array}{c}\text { expected } \\
\text { amplicon size }\end{array}$ & $\begin{array}{c}\text { Ampl. } \\
\text { efficiency } \\
(\%)\end{array}$ & $\begin{array}{l}\text { ENSEMBLE } \\
\text { transcript ID: } \\
\text { ENSGACT... }\end{array}$ \\
\hline aqpla & $\begin{array}{l}\text { FP: TTCACGAACCACTGGGTGTA } \\
\text { RP: TATTTGGGGAACAGCAGGAA }\end{array}$ & 62.0 & 89 & 93 & 00000023023 \\
\hline aqp $3 a$ & $\begin{array}{l}\text { FP: CTATCCCGGAAACCATCTCA } \\
\text { RP: CCAGGACACACACAATCAGC }\end{array}$ & 62.0 & 83 & 97 & 00000013719 \\
\hline аqр $8 a a$ & $\begin{array}{l}\text { FP: CTACCTGTGTGGAGGGATGG } \\
\text { RP: CGTAGGGGAACATGGCTCT }\end{array}$ & 64.0 & 107 & 84 & 00000012065 \\
\hline$a q p 8 a b$ & $\begin{array}{l}\text { FP: CATTTCAACCCTCCCTTCAC } \\
\text { RP: TAGGGTCCCACCATCATCAG }\end{array}$ & 62.0 & 71 & 93 & 00000019179 \\
\hline aqp10a & $\begin{array}{l}\text { FP: CTCCCTCAAAGCTGATTGCT } \\
\text { RP: GTCCCGAGCAGGATTTATTG }\end{array}$ & 62.0 & 101 & 80 & 00000016105 \\
\hline$a q p 10 b$ & $\begin{array}{l}\text { FP: GAGGTTTTCGAGGCTGGAG } \\
\text { RP: TGACGTGGCATCTGTTCTTC }\end{array}$ & 64.0 & 143 & 91 & 00000005857 \\
\hline$n k c c l a$ & $\begin{array}{l}\text { FP: TGTCCTCATCACTGCCATCA } \\
\text { RP:CATAGCCGAAGTAGCCCAGRP }\end{array}$ & 60.0 & 86 & 101 & 00000024304 \\
\hline$n k c c 2$ & $\begin{array}{l}\text { FP: GTGTGGTCAGAGGAGGAGGA } \\
\text { RP: TGGCAAAGGCAAAAATAAGG }\end{array}$ & 60.0 & 93 & 98 & 00000022179 \\
\hline$n c c$ & $\begin{array}{l}\text { FP: GTTCTTGCTGACTTGGTGGG } \\
\text { RP: ACCTCGGGCTTCTTGTAGAC }\end{array}$ & 60.0 & 87 & 102 & 00000003177 \\
\hline$c f t r$ & $\begin{array}{l}\text { FP4: GAGCACATACCTGCGCTACA } \\
\text { RP4: ATGACTGAACCAGCGACCTC }\end{array}$ & 60.0 & 99 & 120 & 00000011967 \\
\hline nka547 & $\begin{array}{l}\text { FP CGAAGGGGAAGAAGAAGGAG } \\
\text { RP CAGAATCTCAGCAGCCTTGG }\end{array}$ & 60.0 & 149 & 102 & 00000018961 \\
\hline nka976 & $\begin{array}{l}\text { FP AGGCGGAGTAGGAAAGTTGC } \\
\text { RP TCTGTGGAGTTCGTCCAAGG }\end{array}$ & 60.0 & 228 & 99 & 00000018945 \\
\hline claudin-2 & $\begin{array}{l}\text { FP: CCTTCCAATGCGAGACCTAC } \\
\text { RP: GACAGCACGAGGGAGATGAC }\end{array}$ & 64.0 & 91 & 86 & 00000027597 \\
\hline claudin-15a & $\begin{array}{l}\text { FP: ATGTGCACAATGGTTGCAGT } \\
\text { RP: ACCTTATTCCGGGATGGAAG }\end{array}$ & 60.0 & 82 & 94 & 00000025514 \\
\hline spiggin & $\begin{array}{l}\text { FP: GCTGCTCTTGTGAGTTTGCTG } \\
\text { RP: TCGCCATTTCCCACCATC }\end{array}$ & 60.0 & 95 & 105 & 00000025232 \\
\hline b-actin & $\begin{array}{l}\text { FP: GCGTGGCTACTCCTTCACC } \\
\text { RP: AGGACTCCATACCGAGGAAGG }\end{array}$ & 68.4 & 230 & 94 & 00000010448 \\
\hline ubiquitin & $\begin{array}{l}\text { FP: AGACGGGCATAGCACTTGC } \\
\text { RP: CAGGACAAGGAAGGCATCC }\end{array}$ & 69.5 & 218 & 102 & 00000010662 \\
\hline
\end{tabular}


Table 2. Alignment analysis of amino acids of the first extracellular loop from selected claudin isoforms: human (homo) claudin-2 (acc. no. NP065117.1) and -15 (NP055158); zebrafish (danio) claudin-2 (NP001004559.2) and -15a (NP956698) and stickleback (gac) claudin-2 (ENSGACP00000027545.1) and -15 (ENSGACP00000025464.1). Acidic and basic amino acids are highlighted in red and blue respectively. Hydrophobic and hydrophillic residues are highlighted in black and green, respectively.

homo claudin2: gac claudin2: danio claudin2: MECATHSTGITQCDIYSTILGLPADIQAAQ MECVYQSTGAFQCETYNSMIALSPDLQASR MECVYQSTGAFQCETYNTILGLTVDLQAAR

homo claudin15: gac claudin15a: FSCATDSIGVYNCWEFPSMIAISSGYQACF danio claudin15a: MSCATDSTGVHNCREFPSIIALSGYIQASR MSCATDSTGVHQCREFPSIIAISGYIQASR 
Figure 1
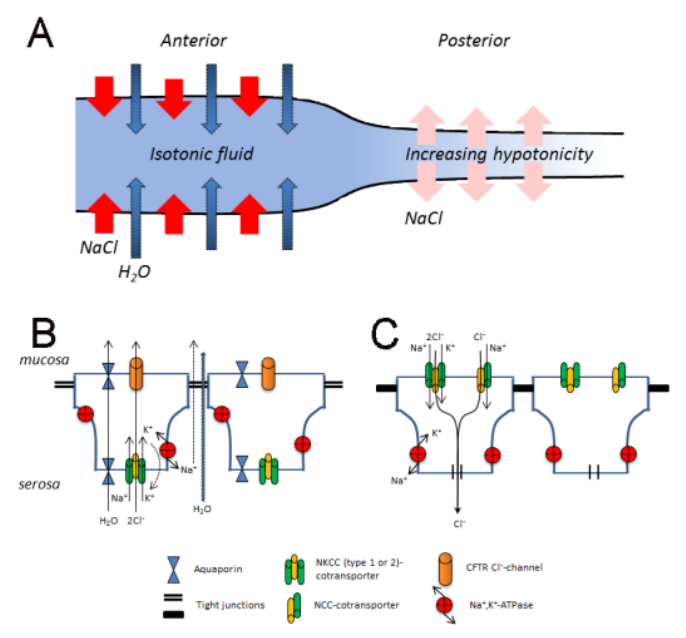

\section{Figures}


A

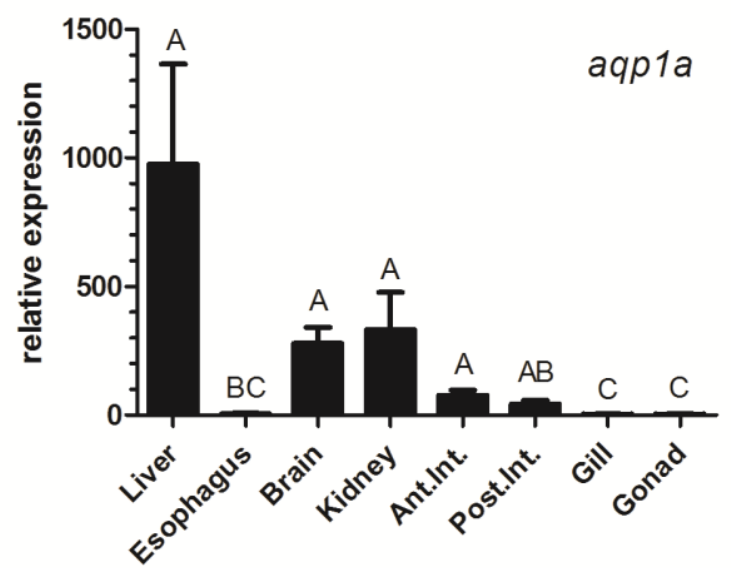

C

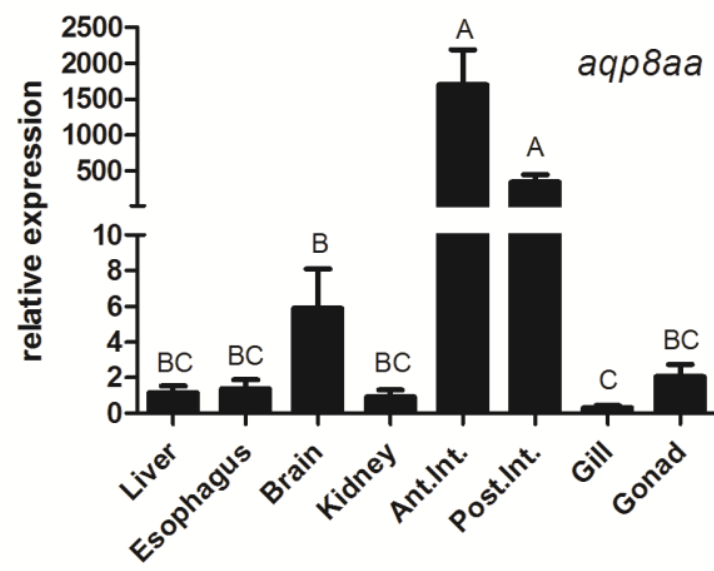

E

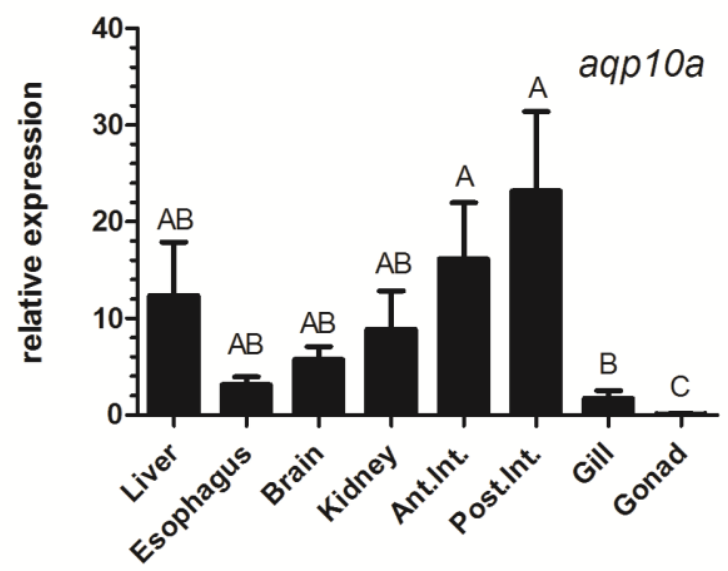

B

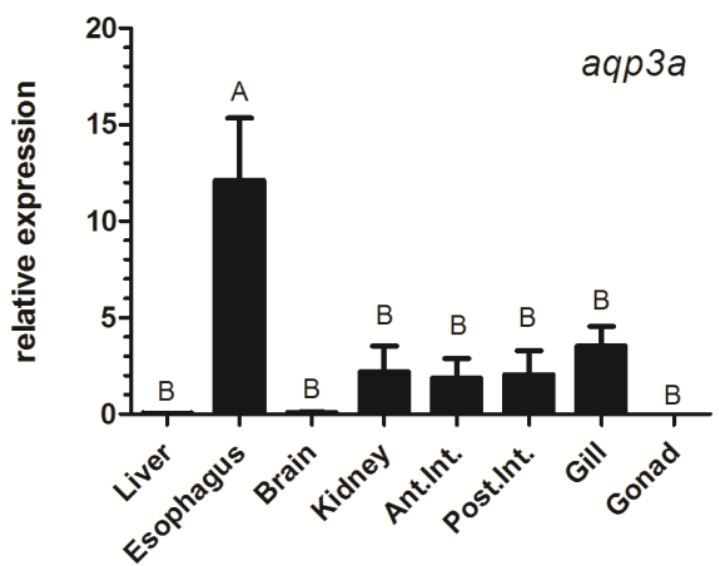

D

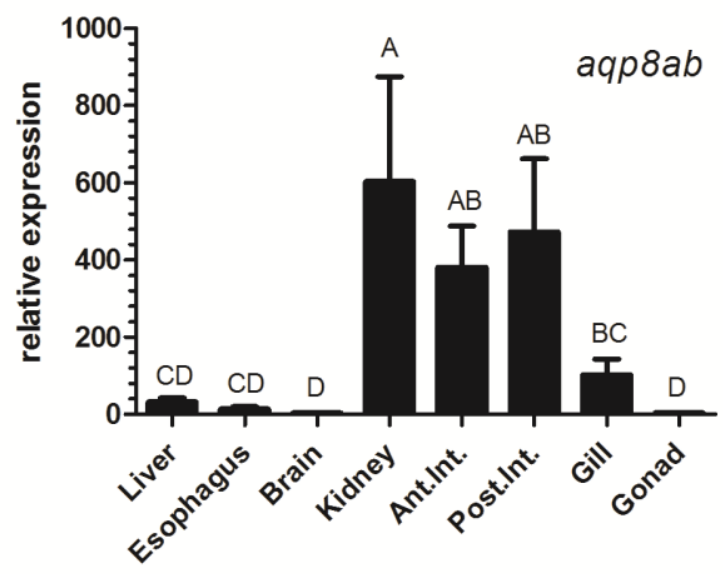

F

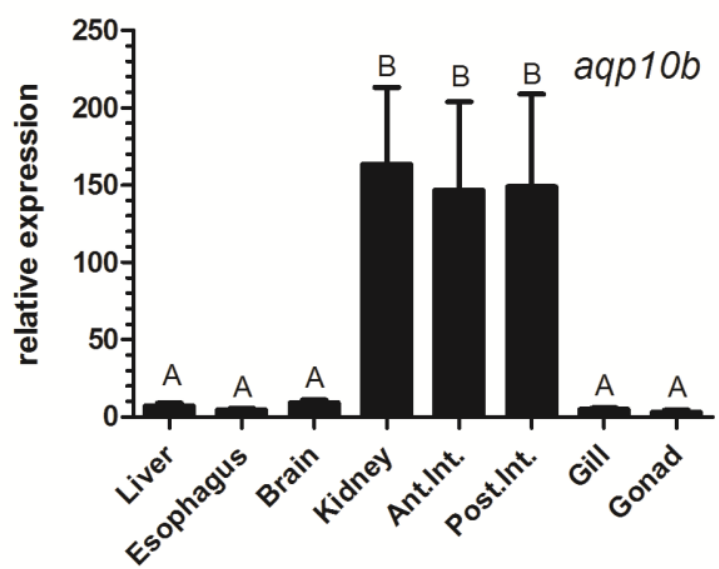


A
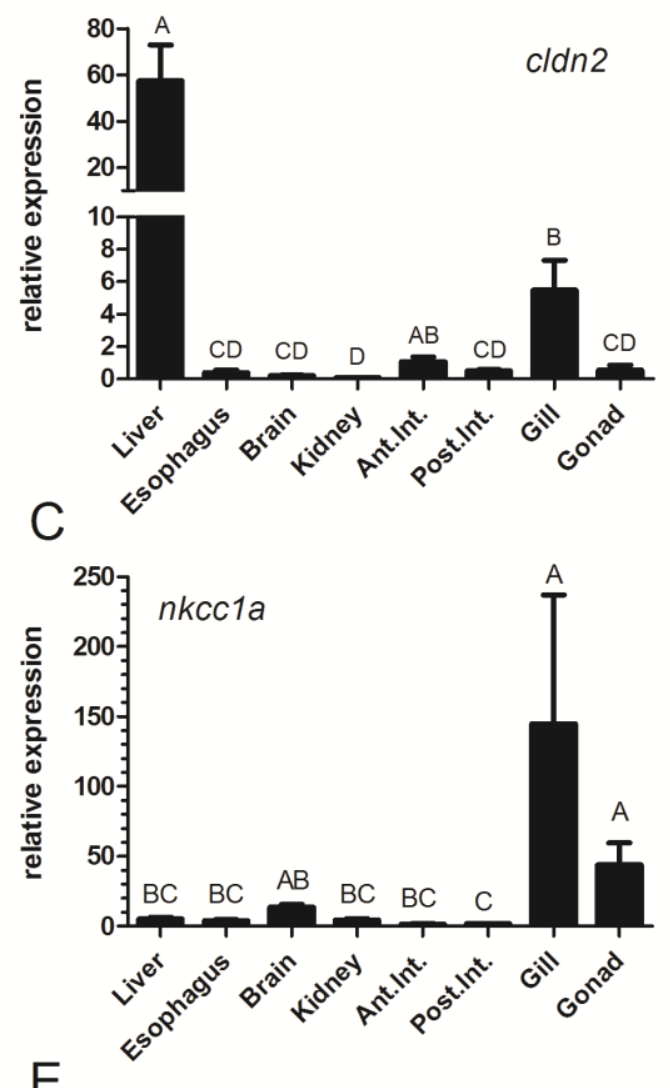

E

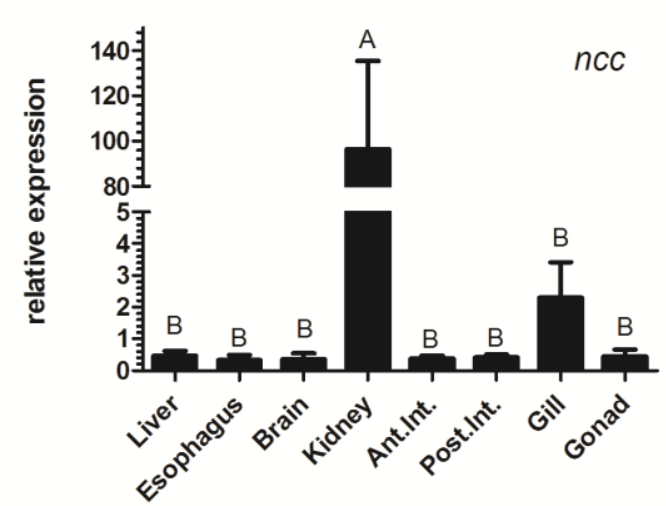

G

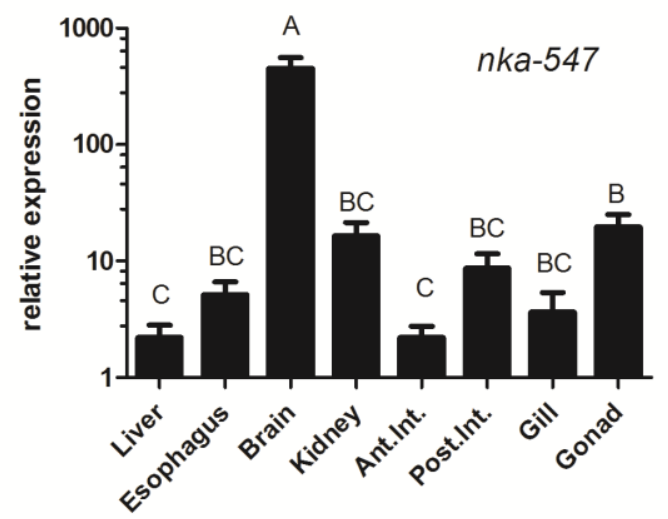

B
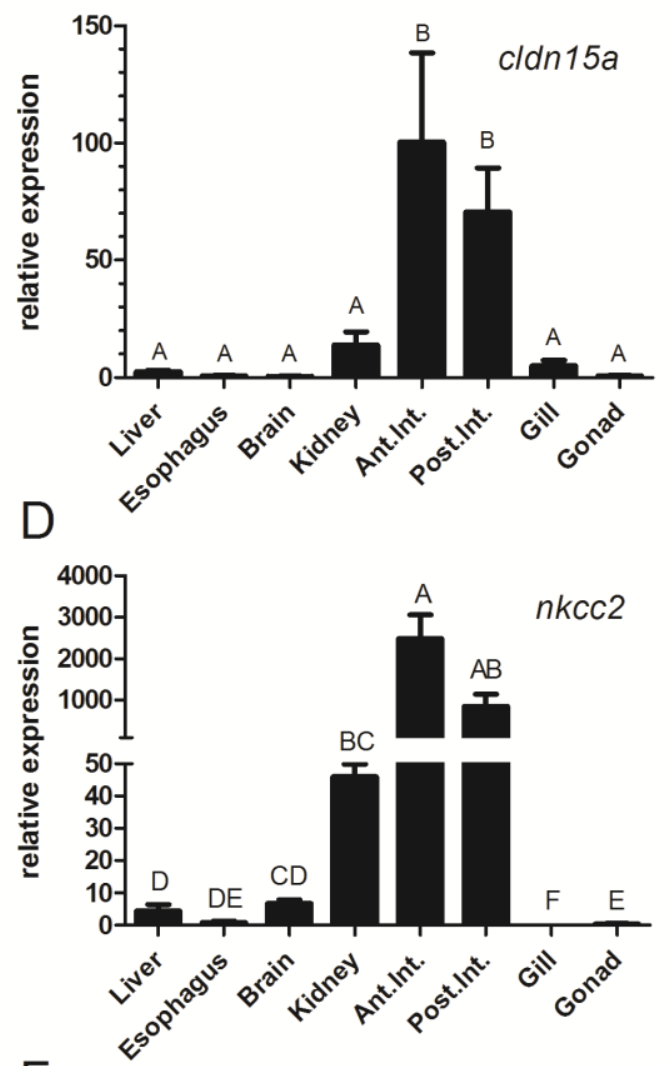

F

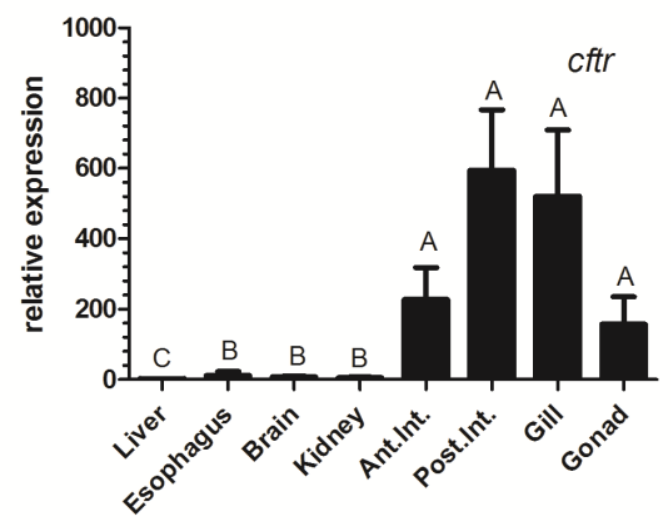

$\mathrm{H}$

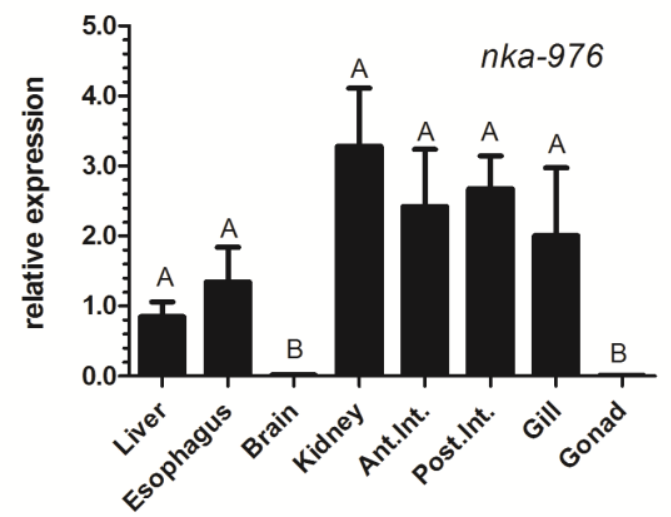




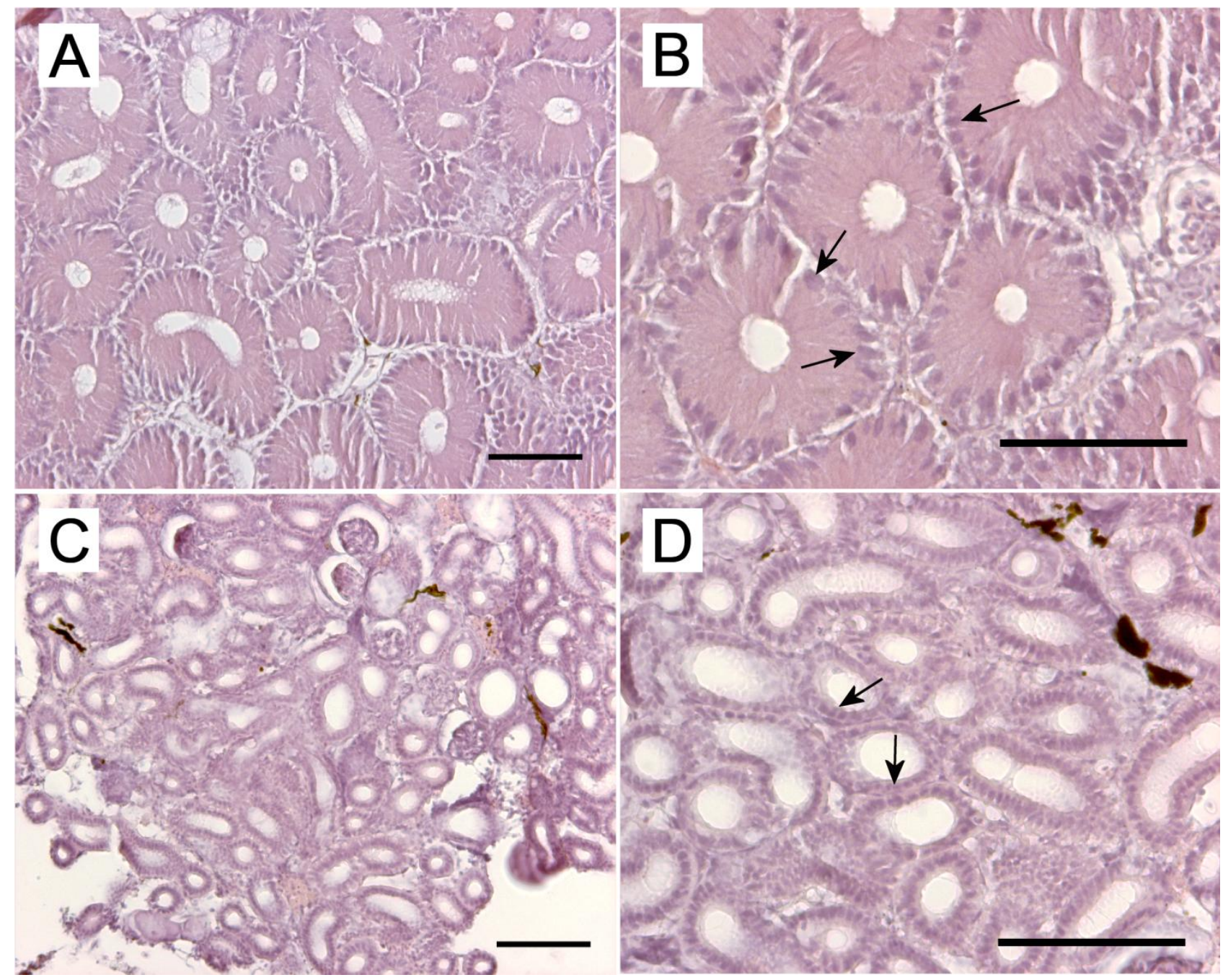


Figure 5

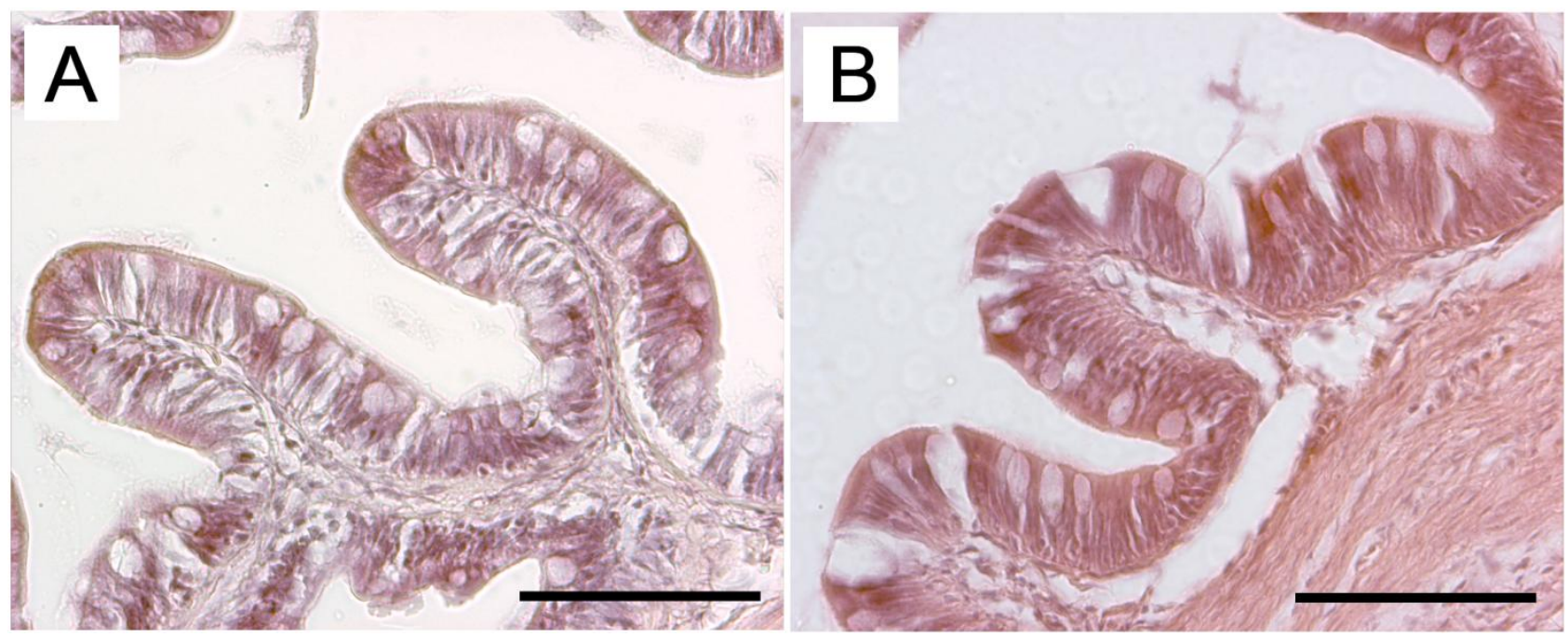




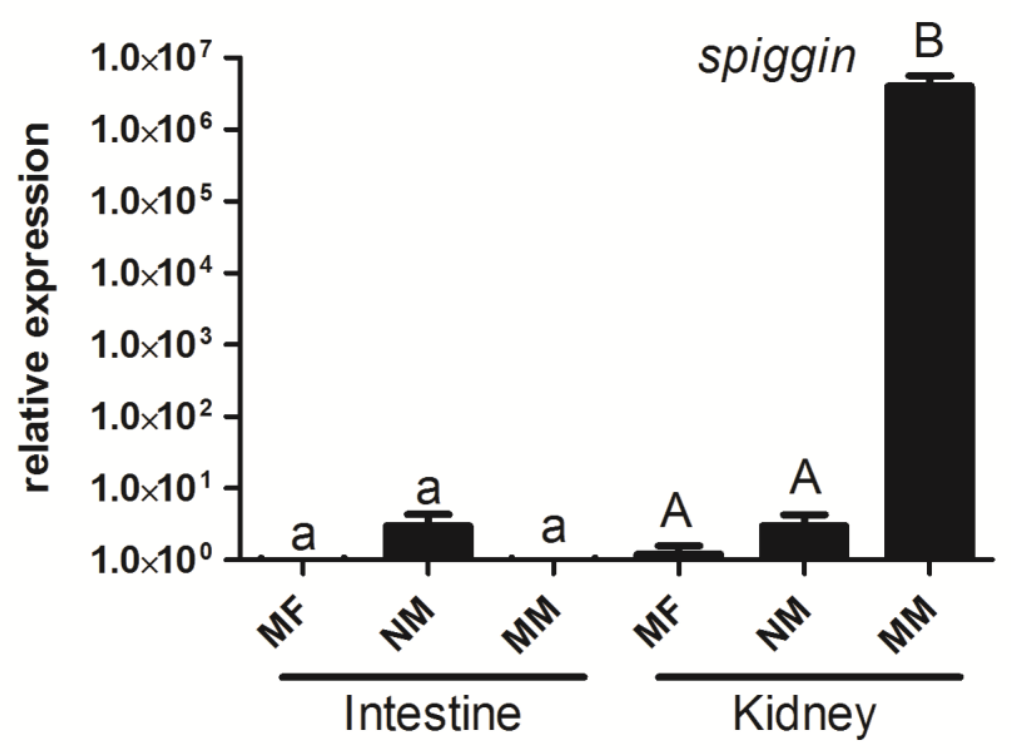


A

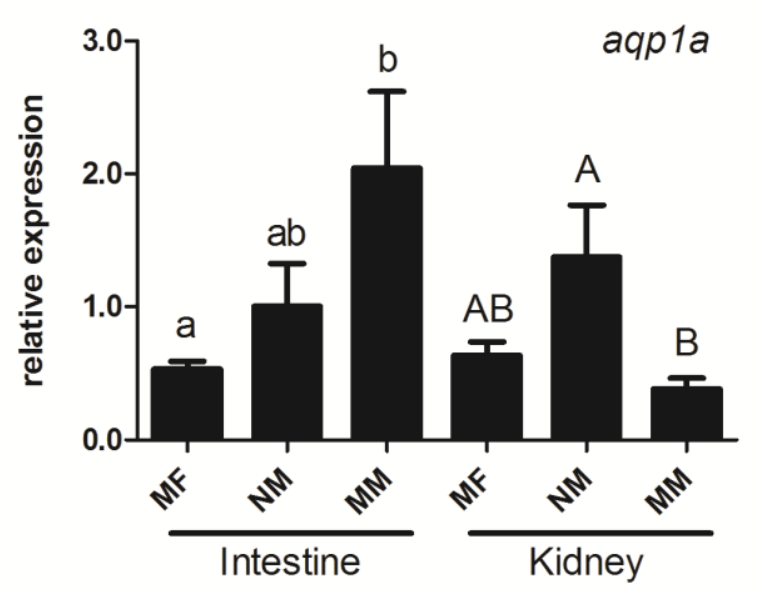

C

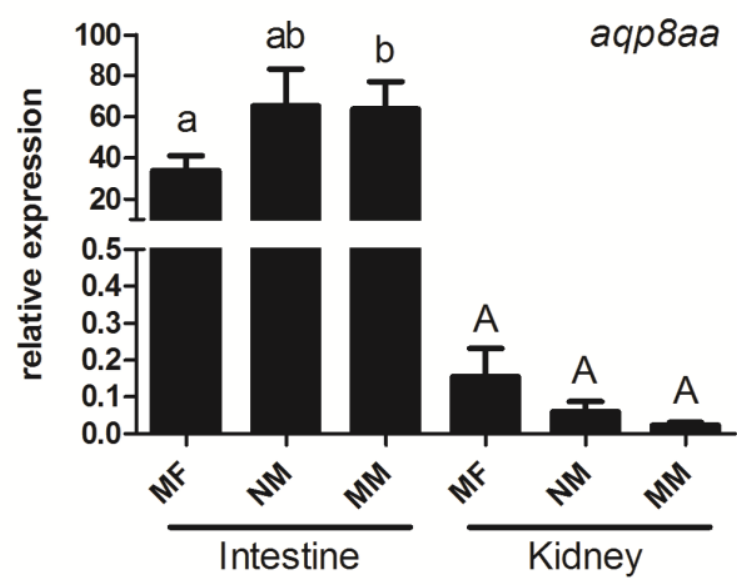

E

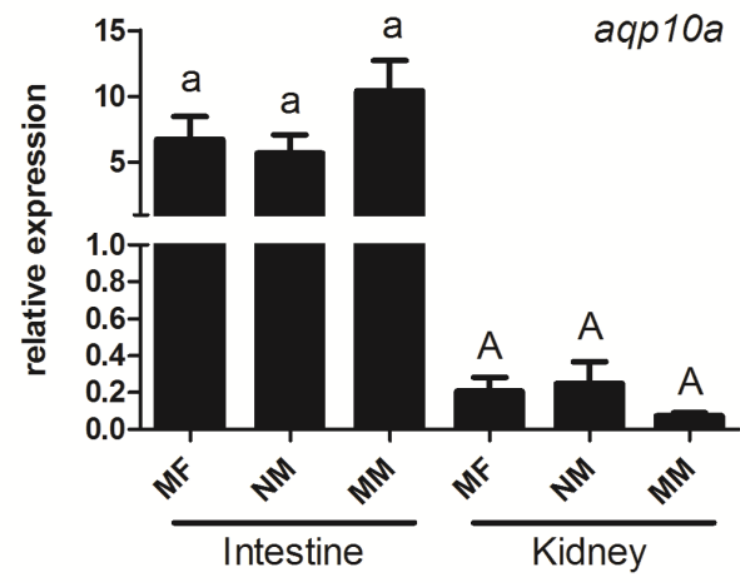

B

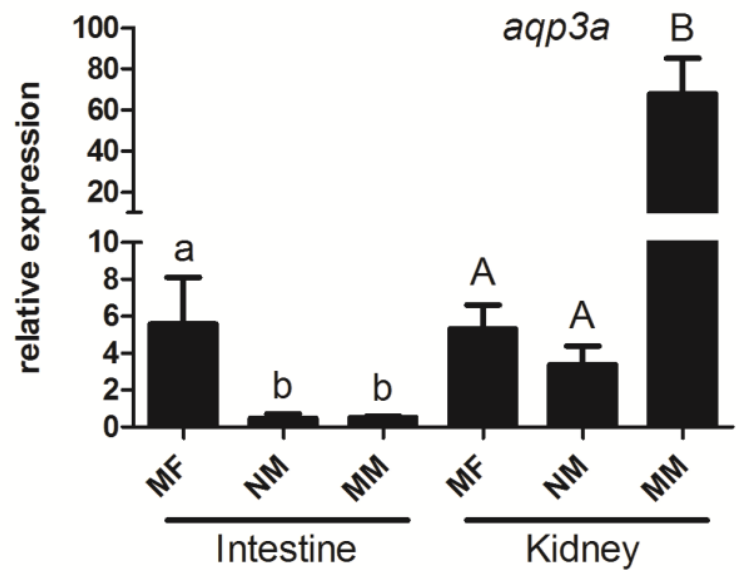

D

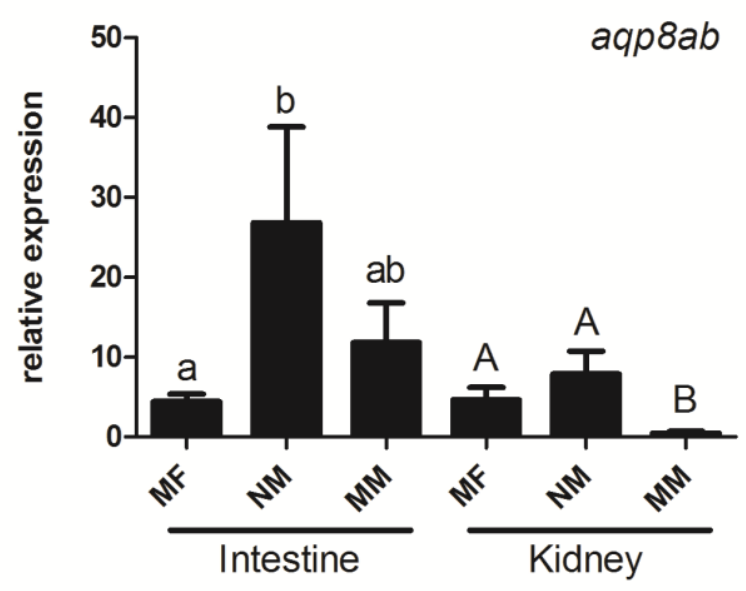

F

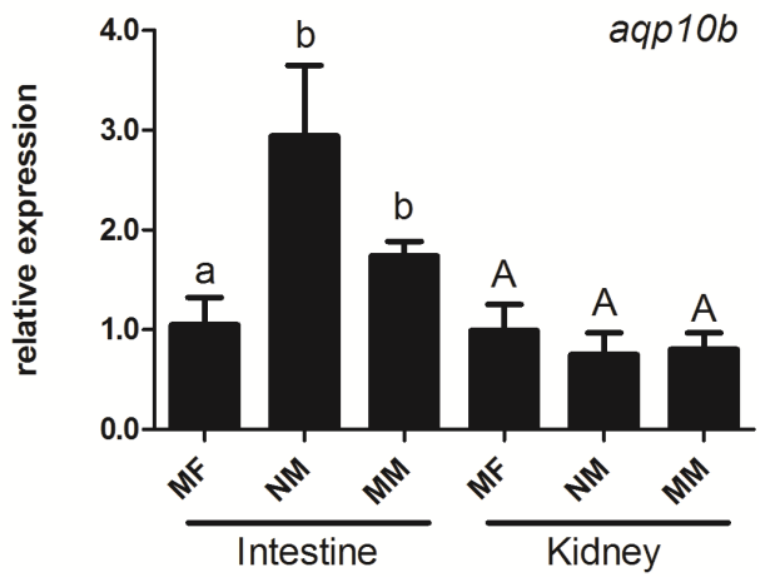


A
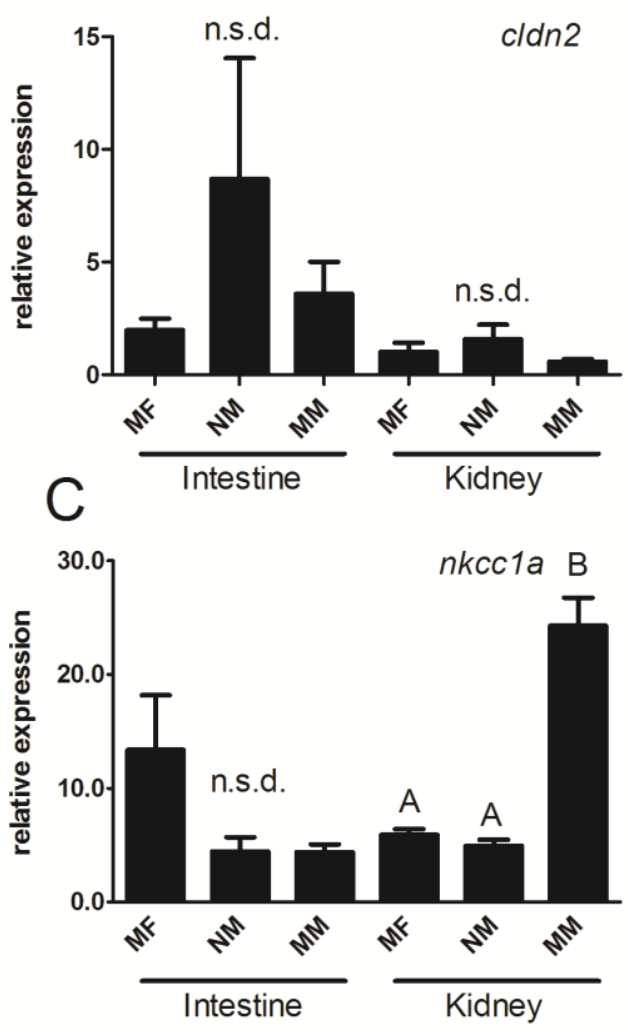

E

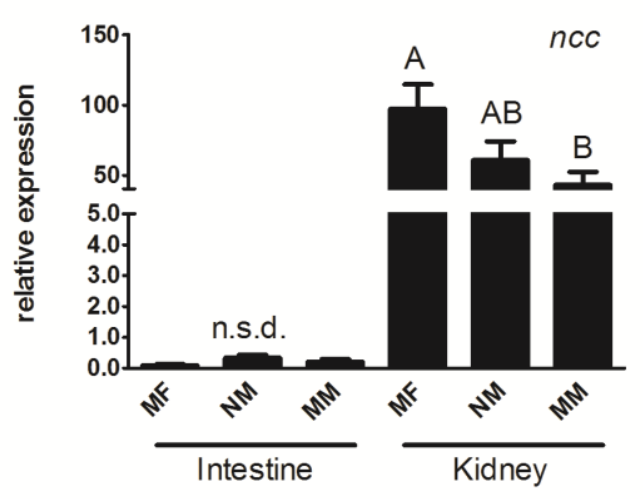

G

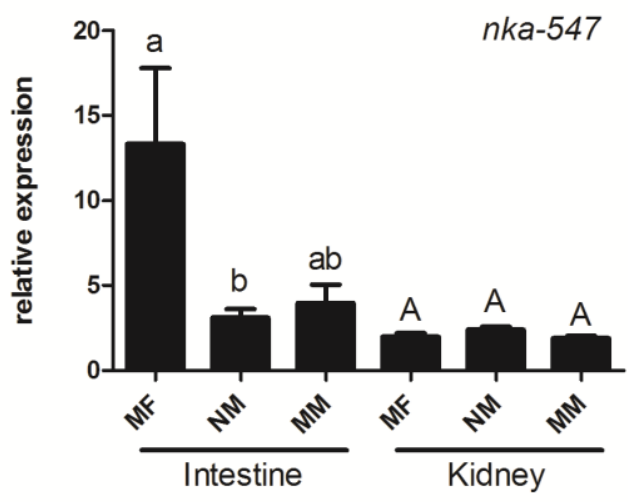

B
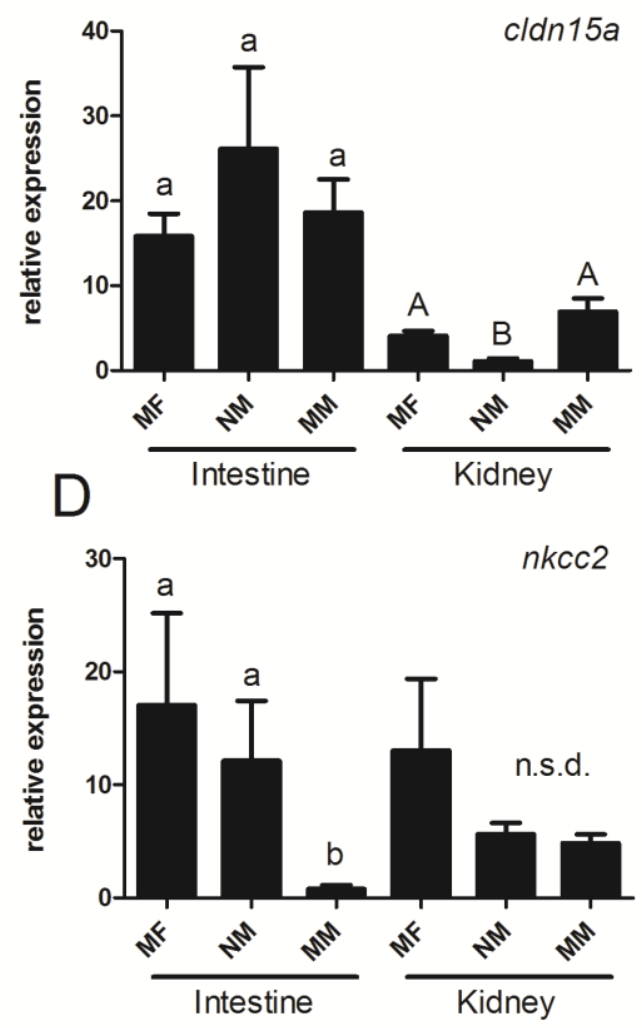

F

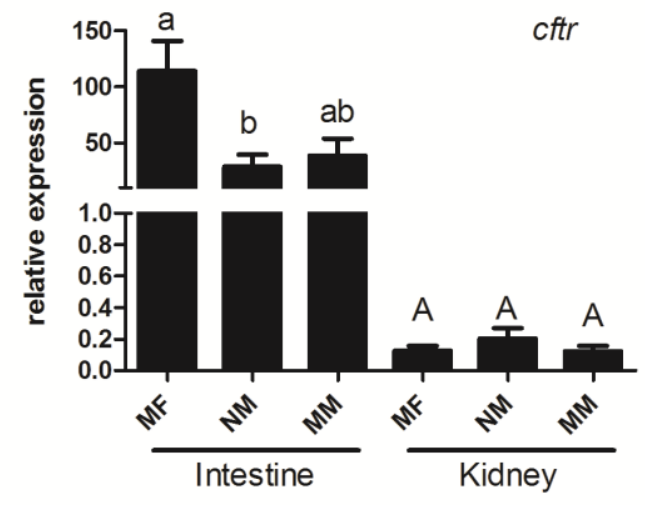

$\mathrm{H}$

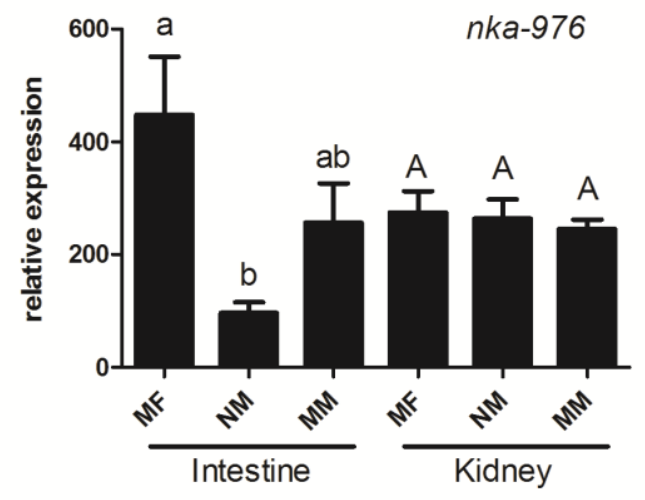

